\title{
Radiological Considerations in the Operation of the Low-Energy Undulator Test Line (LEUTL)
}

April 10, 1998

H. J. Moe

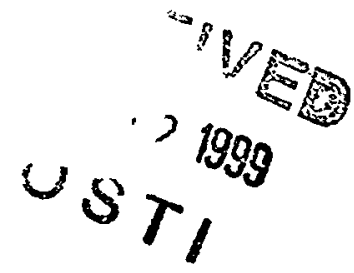

\section{General}

The Low-Energy Undulator Test Line (LEUTL) is a facility that uses the existing APS linac to accelerate electrons up to an energy of $700 \mathrm{MeV}$. These electrons are transported through the PAR into a portion of the booster synchrotron and on into the LEUTL main enclosure (MIL 97). Figure 1 shows the layout of the LEUTL building, which consists of an earth-bermed concrete enclosure and an end-station building. The concrete enclosure houses the electron beamline, test undulator, and beam dump. This facility is about $51 \mathrm{~m}$ long and $3.66 \mathrm{~m}$ wide. Technical components and diagnostics for characterizing the undulator light are found in the end station. This building has about $111 \mathrm{~m}^{2}$ of floor space.

This note deals with the radiological considerations of operations using electrons up to $700 \mathrm{MeV}$ and at power levels up to the safety envelope of $1 \mathrm{~kW}$. Previous radiological considerations for electron and positron operations in the linac, PAR, and synchrotron have been addressed elsewhere (MOE 93a, 93b, and 93c). Much of the methodology discussed in the previous writeups, as well as in MOE 94, has been used in the computations in this note. The radiological aspects that are addressed include the following: prompt secondary radiation (bremsstrahlung, giant resonance neutrons, medium- and high-energy neutrons) produced by electrons interacting in a beam stop or in component structures; skyshine radiation, which produces a radiation field in nearby areas and at the nearest off-site location; radioactive gases produced by neutron irradiation of air in the vicinity of a particle loss site; noxious gases (ozone and others) produced in air by the escaping bremsstrahlung radiation that results from absorbing particles in the components; activation of the LEUTL components that results in a residual radiation field in the vicinity of these materials following shutdown; potential activation of water used for cooling the magnets and other purposes in the tunnel; and evaluation of the radiation fields due to escaping gas bremsstrahlung. Estimated dose rates have been computed or scaled (in the case of $400 \mathrm{MeV}$ electrons) outside of the bermed tunnel, in Building 412, and in the Klystron Gallery for several modes of operation, including potential safety envelope beam power, normal beam power and MCI (maximum credible incident) conditions. Radiological aspects of shielding changes to the synchrotron and their effect upon operations are addressed in MOE 97 . No change in the safety envelope for synchrotron operation was warranted.

\section{Beam Parameters and LEUTL Tunnel Information}

Computations have been based upon these parameters for Design Performance Goal LEUTL operations with electrons: $30 \mathrm{nC} / \mathrm{p}, 10$ pulses/s and an electron energy of $400 \mathrm{MeV}$. This gives a 


\section{DISCLAIMER}

This report was prepared as an account of work sponsored by an agency of the United States Government. Neither the United States Government nor any agency thereof, nor any of their employees, make any warranty, express or implied, or assumes any legal liability or responsibility for the accuracy, completeness, or usefulness of any information, apparatus, product, or process disclosed, or represents that its use would not infringe privately owned rights. Reference herein to any specific commercial product, process, or service by trade name, trademark, manufacturer, or otherwise does not necessarily constitute or imply its endorsement, recommendation, or favoring by the United States Government or any agency thereof. The views and opinions of authors expressed herein do not necessarily state or reflect those of the United States Government or any agency thereof. 


\section{DISCLAIMER}

Portions of this document may be illegible in electronic image products. Images are produced from the best available original document. 
Figure 1. LEUTL building with the end station.

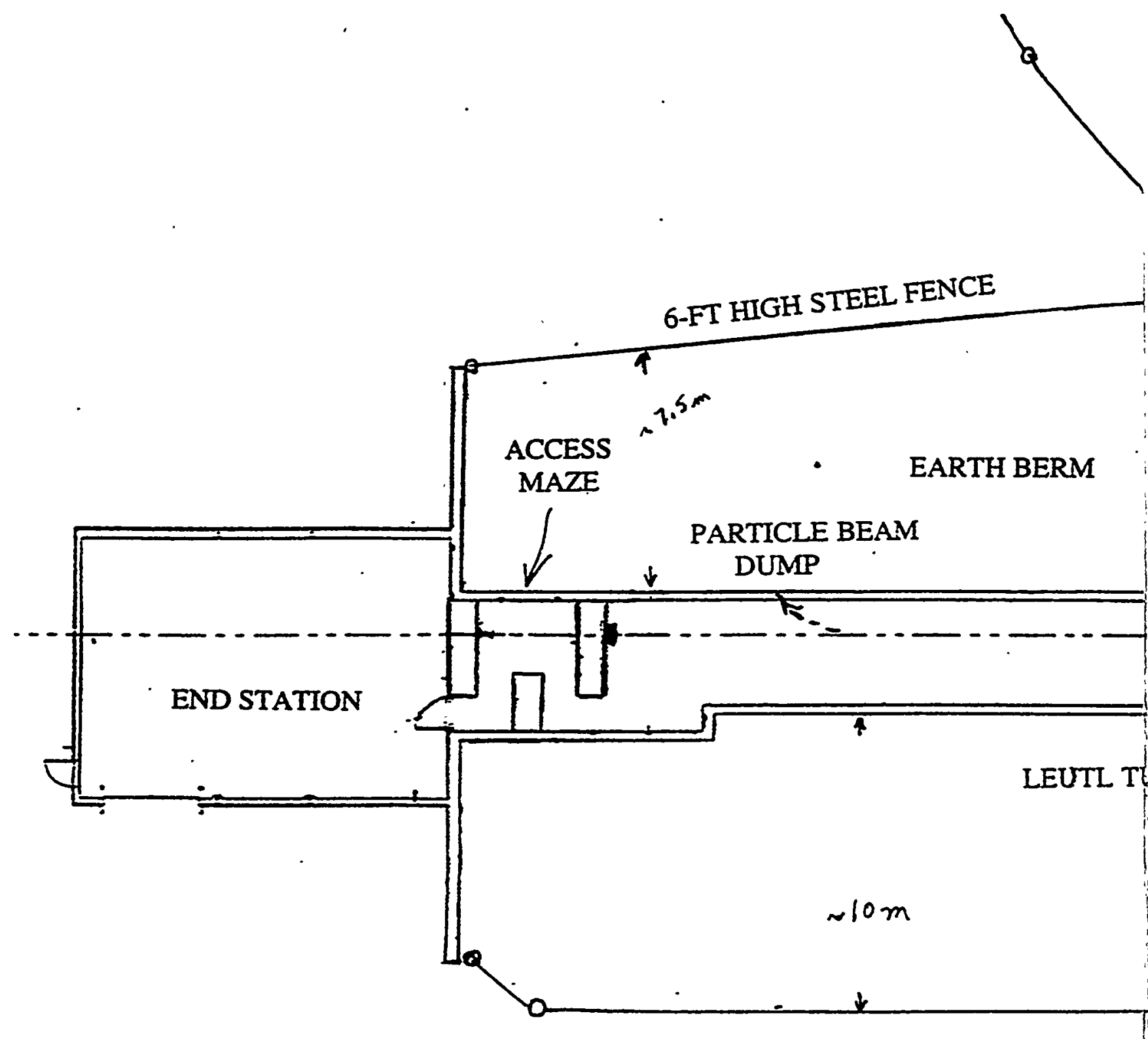

6-FT HIGH STEEL FENCE

1 inch $=5.431 \mathrm{~m}$ 


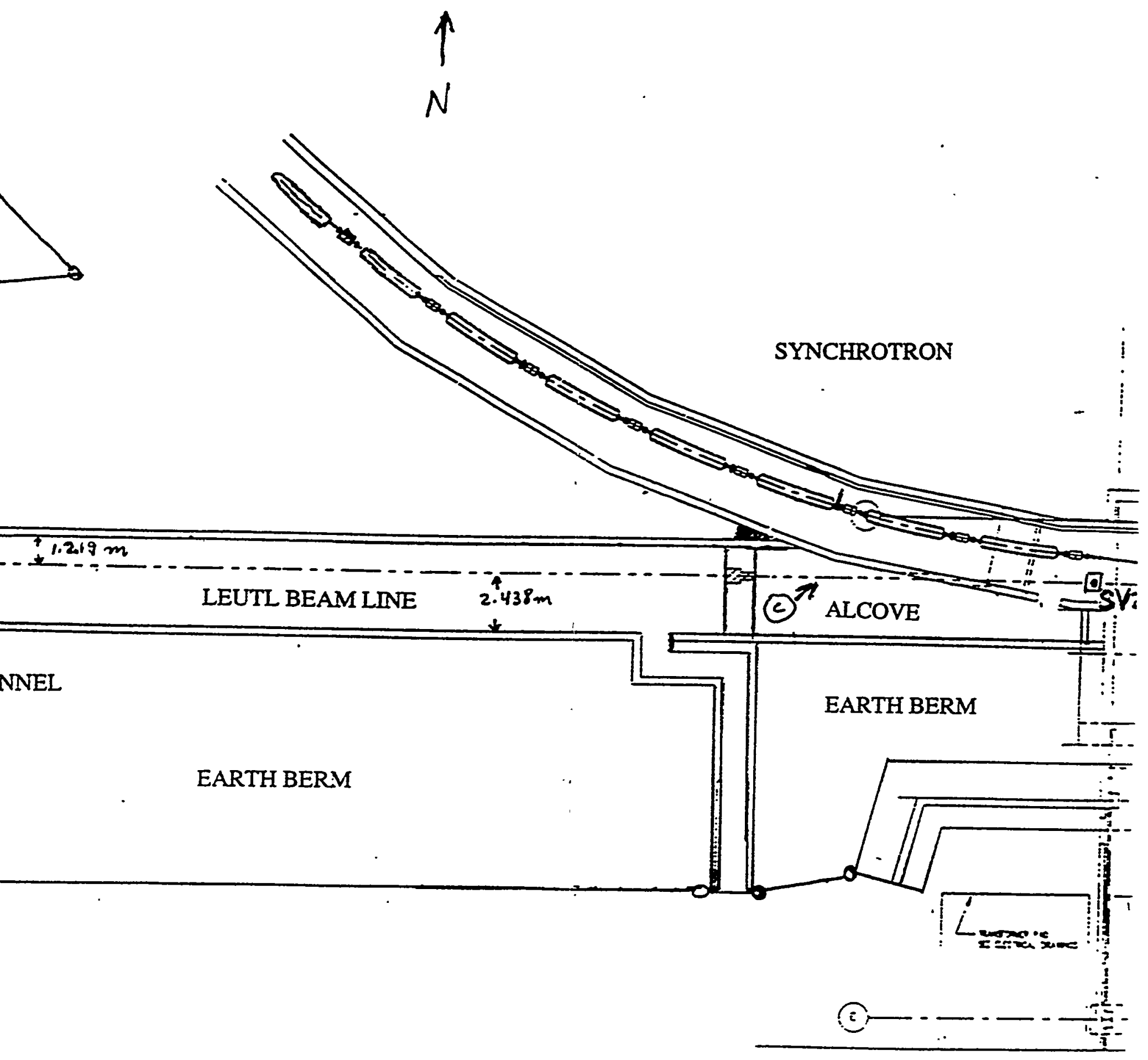


beam power of $120 \mathrm{~W}$ at the end of the linac that is sent through the PAR into the synchrotron. This beam travels either to the LEUTL to be used to produce light in the undulators or to the synchrotron beam dump. If sent to the LEUTL, the electron beam is bent into a beam dump by a permanent magnet near the end of the LEUTL line following its use to produce light. For operation at the linac safety envelope of $1000 \mathrm{~W}$, a maximum energy of $700 \mathrm{MeV}$ at an average current of $1.428 \mu \mathrm{A}$ is assumed (e.g., $\sim 48$ pulses/s at $30 \mathrm{nC} /$ pulse or some other suitable product of repetition rate and charge per pulse).

The LEUTL tunnel is about $51 \mathrm{~m}$ in length and $3.658 \mathrm{~m}$ in width, except for about the last $8 \mathrm{~m}$, where the width is $4.572 \mathrm{~m}$. The LEUTL beamline is $1.4 \mathrm{~m}$ above the floor level and $1.219 \mathrm{~m}$ from the north wall, entering from the east through an alcove and a 1.219-m normal concrete wall, after it leaves the synchrotron. The beamline is long enough to accommodate about $30 \mathrm{~m}$ of undulators before it is deflected by a permanent magnet into a beam dump. The light formed in the undulators is deflected and sent through the two normal concrete walls (each $0.914 \mathrm{~m}$ in thickness) of the access maze and is analyzed in the end station building. A beam stop in front of the first concrete wall of the access maze will stop the particle beam should the permanent magnet fail to deflect the beam. The walls of the tunnel are normal concrete $(30.5 \mathrm{~cm}$ thick) and the ceiling is $38.1 \mathrm{~cm}$ of normal concrete. The density of the concrete is $2.35 \mathrm{~g} / \mathrm{cc}$. The concrete of the tunnel is supplemented by an earth berm covering the tunnel and the entire area is fenced off by a $1.83-\mathrm{m}$ high steel fence. The earth berm on the north side of the tunnel joins with the existing earth berm for the synchrotron in a fenced-in area. The maze shown at the east end of the LEUTL tunnel is used as an emergency exit only. Not shown is the provision for a future second beamline.

The LEUTL line begins in the linac and utilizes the existing linac line for acceleration and transport of the electrons. Electrons are accelerated from a few $\mathrm{MeV}$ to $700 \mathrm{MeV}$. At the bend point into the PAR, the modifications include removal of the $\mathrm{Pb}$ stop in the forward direction, addition of a new beamline through the PAR and on into the synchrotron, inclusion of a double tungsten stop to prevent unwanted beam from going to the synchrotron, and changes to the shield wall between the PAR and synchrotron to accommodate the new LEUTL beamline (see Figure 2). The LEUTL line continues in a straight line through the synchrotron, rising in height to a meter above the synchrotron beam, and is bent through a penetration in the synchrotron wall toward the LEUTL tunnel (see Figure 3). A beam stop on the floor is provided downstream of the point where the electron beam is bent upwards at the east end of the synchrotron. Provision is made so that the beam can be directed into this beam dump, for use of the LEUTL line up to that point.

\section{Radiation Dose Rates}

\subsection{Bremsstrahlung Dose Rates}

The unshielded bremsstrahlung dose profile angular dependence was estimated from an expression adapted from Swanson, et al. (SWA 85):

$$
\mathrm{H}_{\mathrm{B}}\left(\theta_{\mathrm{B}}\right)=16.7 \mathrm{E}_{\mathrm{o}}\left(2^{-\theta_{\mathrm{B}} / \theta_{1 / 2}}\right)+833\left(10^{-\theta_{B} / 21}\right)+25\left(10^{-\theta_{B} / 110}\right) \mathrm{mrem} / \mathrm{J} \text { at } 1 \mathrm{~m}
$$


Figure 2. PAR bypass line used for LEUTL.

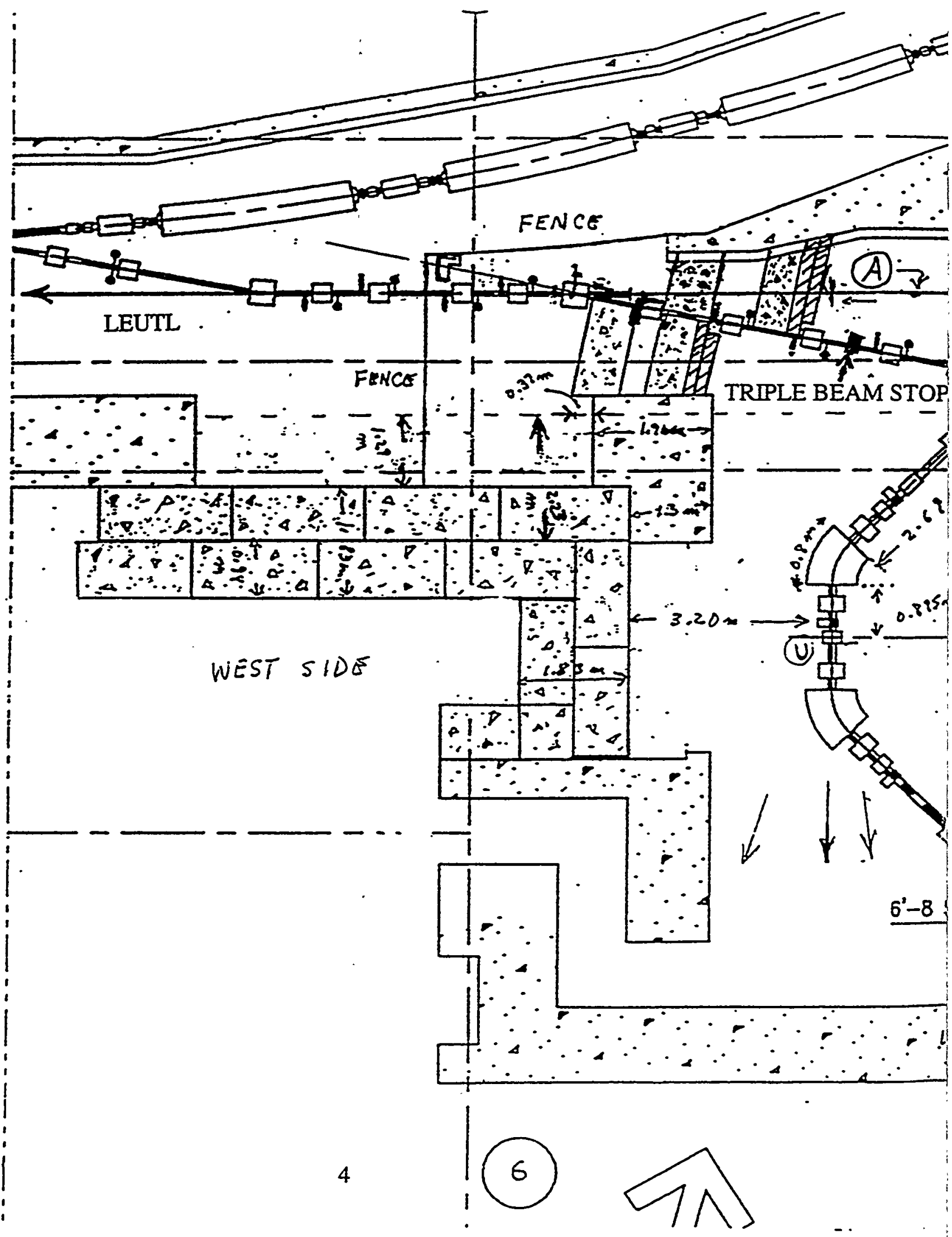


$31.8 \mathrm{~m}$ from target to LWix. GPP $13.61 \mathrm{~m}$ sorsh Lathe wP ro BaND POINT llom tron BexidPr. To Bows pr.

EARTH BERM -

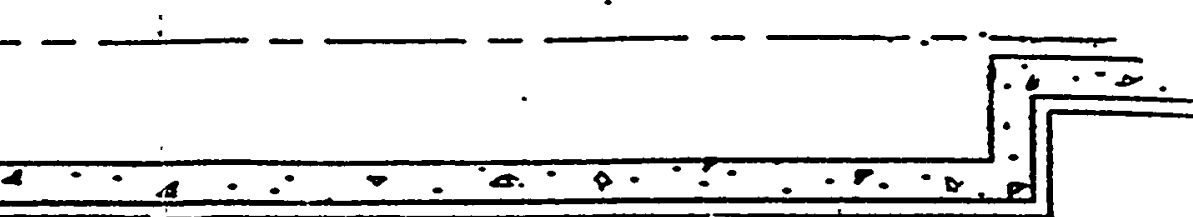
PAR BY-PASS LINE DOUBLE BEAM STOP LEUTL

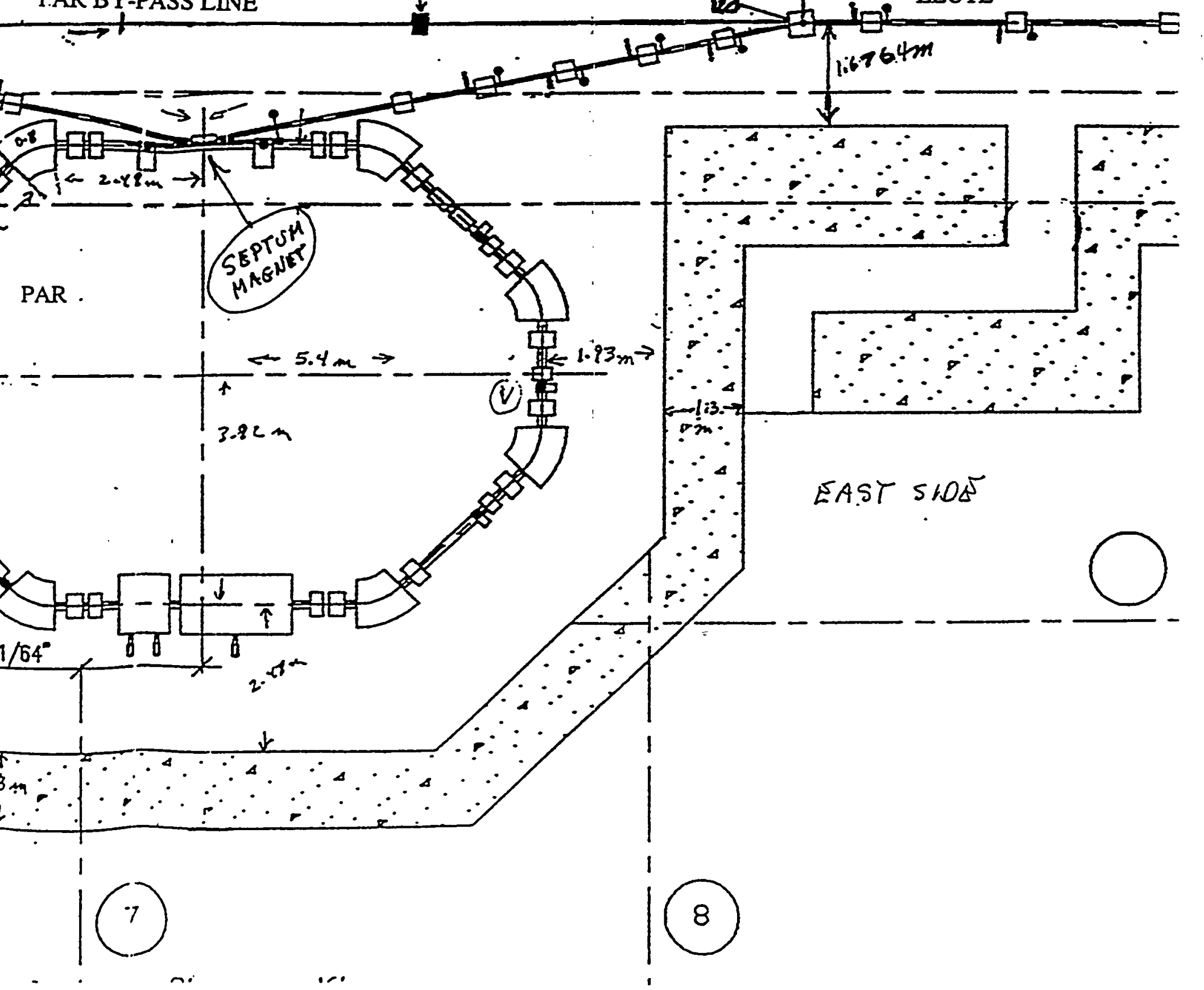


Figure 3. LEUTL line in synchrotron. Upper drawing shows elevation of line.

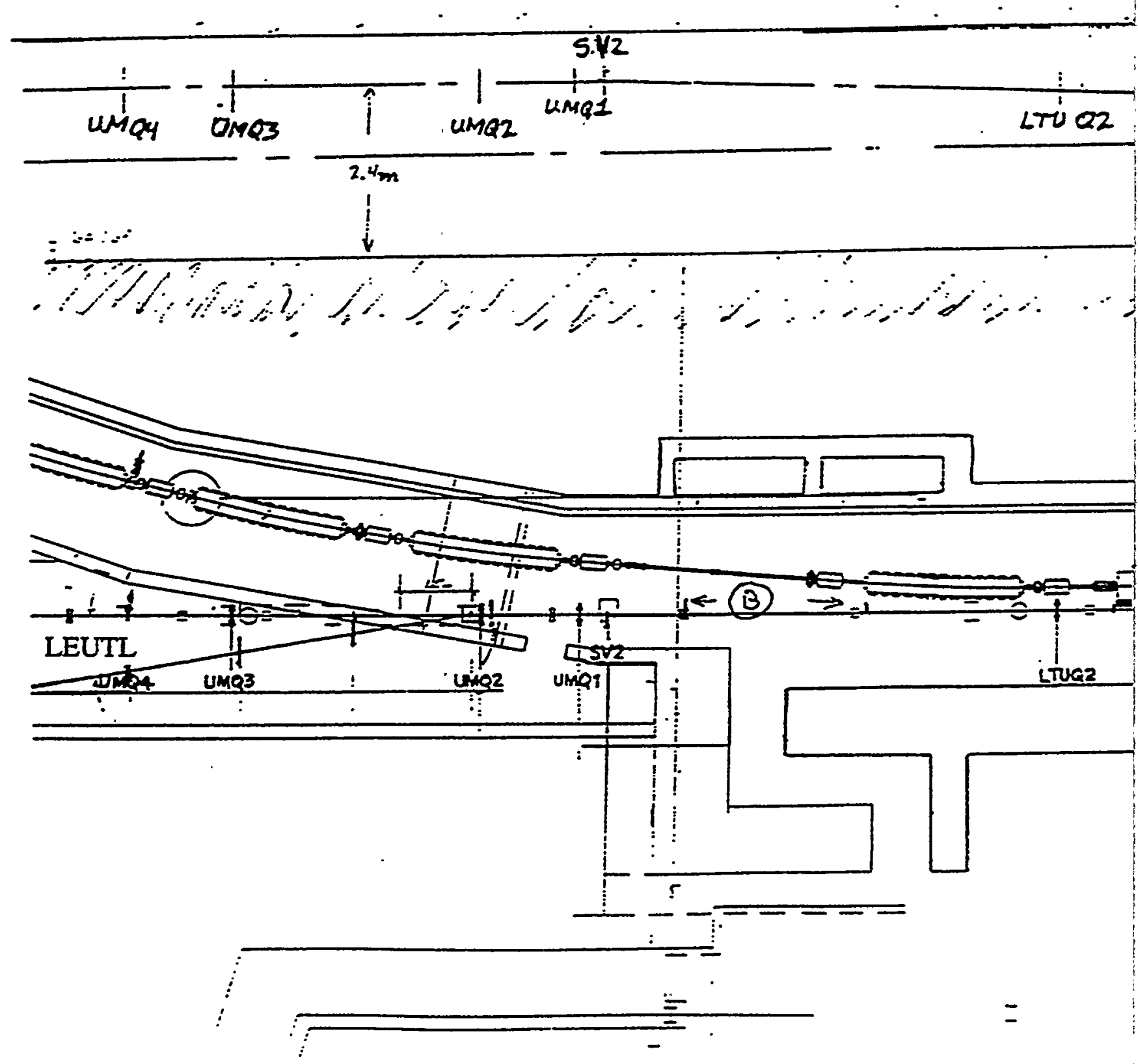




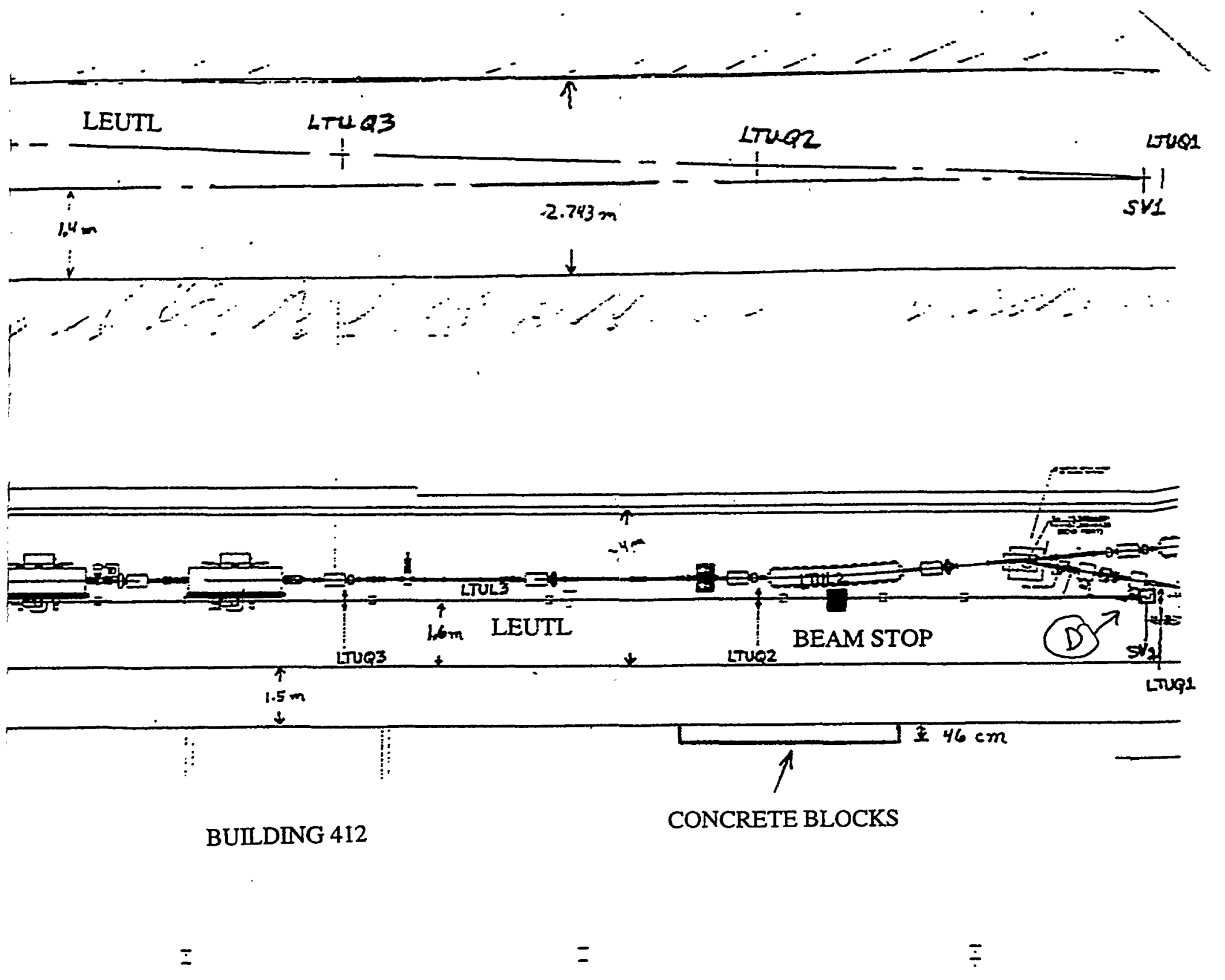


where $E_{0}=$ the electron energy in $\mathrm{MeV}, \theta_{1 / 2}=100 / \mathrm{E}_{\mathrm{o}}$ deg, and $\theta_{\mathrm{B}}$ is the angle between the forward direction of the electron beam at the point where it strikes the component and the line segment from that point to the dose point. The first term in the expression accounts for the intense, highly peaked forward component of the bremsstrahlung, and the remaining two terms give the contribution at the other angles. The dose factor is applicable to cases where the stored beam is being lost. The factor can be expressed as a dose equivalent rate factor at 1 meter by multiplying each term by the energy loss rate in $\mathrm{J} / \mathrm{h}(3600 \mathrm{~W}$, where $\mathrm{W}$ is in watts). The dose rate factor is applicable to the case of injection where losses at a site continue at a given frequency rate. The factor becomes

$$
\begin{aligned}
\dot{\mathrm{H}}_{\mathrm{B}}\left(\theta_{\mathrm{B}}\right)= & 6.012 \times 10^{4} \mathrm{E}_{\mathrm{o}} \mathrm{W}\left(2^{-\theta_{\mathrm{B}} / \theta_{1 / 2}}\right)+3.0 \times 10^{6} \mathrm{~W}\left(10^{-\theta_{\mathrm{B}} / 21}\right) \\
& +9.0 \times 10^{4} \mathrm{~W}\left(10^{-\theta_{\mathrm{B}} / 110}\right) \mathrm{mrem} / \mathrm{h} \text { at } 1 \mathrm{~m} .
\end{aligned}
$$

\subsection{Giant Resonance Neutron (GRN) Dose Rate}

The distribution with angle for the giant resonance neutron (GRN) component was taken as isotropic. The GRN neutron yield in the injection septum and/or SR components was based on (SWA 79):

$$
Y=1.21 \times 10^{8} Z^{0.66}(n / J)
$$

Using a conversion factor of about $7 \mathrm{n} / \mathrm{cm}^{2} \mathrm{~s}=1 \mathrm{mrem} / \mathrm{h}$, the dose equivalent factor at 1 meter for the GRN component can be approximated by $0.33 \mathrm{mrem} / \mathrm{J}$ at $1 \mathrm{~m}$ for steel components which, for a $1000-W$ loss, gives a dose rate of

$$
\dot{\mathrm{H}}_{\mathrm{GRN}}=1.19 \times 10^{6} \mathrm{mrem} / \mathrm{h} \text { at } 1 \mathrm{~m} \text { unshielded. }
$$

The corresponding dose equivalent factor for copper is $0.35 \mathrm{mrem} / \mathrm{J}$.

\subsection{Medium and High Energy Neutron Dose Rates}

Dose equivalent factors for the medium energy neutron (MEN) and high energy neutron (HEN) components at $90^{\circ}$ from a Cu target were taken from CERN 84-02 (CER 84). The variation with angle is given by Jenkins (JEN 79). The angular relationships of Jenkins are

$$
\begin{aligned}
& F(\theta)_{\mathrm{MEN}}=F\left(90^{\circ}\right)_{\mathrm{MEN}} /(1-0.75 \cos \theta), \\
& \mathrm{F}(\theta)_{\mathrm{HEN}}=\mathrm{F}\left(90^{\circ}\right)_{\mathrm{HEN}} /(1-0.72 \cos \theta)^{2},
\end{aligned}
$$

in which $\mathrm{F}\left(90^{\circ}\right)_{\mathrm{MEN}}=2.65 \times 10^{-2} \mathrm{mrem} / \mathrm{J}$ at $1 \mathrm{~m}$ and $\mathrm{F}\left(90^{\circ}\right)_{\mathrm{HEN}}=2.48 \times 10^{-3} \mathrm{mrem} / \mathrm{J}$ at $1 \mathrm{~m}$ for $700 \mathrm{MeV}$ electrons. High-energy neutron production decreases with increasing Z, and Tesch (TES 88) gives the theoretical correction factor of 1.86 for $\mathrm{Al}$ and the factor 0.6 for neutron production 
in high $\mathrm{Z}$ materials ( $\mathrm{W}$ and $\mathrm{Pb}$ ), relative to copper. Since iron and copper are close in atomic number, the production values in $\mathrm{Cu}$ have been assumed for $\mathrm{Fe}$. Combining the factors above (dose constant and $Z$ correction), the revised unshielded dose factors at $1 \mathrm{~m}$ for steel components, as a function of the emission angle $\theta$, become:

Steel Component

$(\mathrm{mrem} / \mathrm{J}$ at $1 \mathrm{~m})$

\begin{tabular}{rcc}
\hline Angle & MEN & HEN \\
\hline $0^{\circ}$ & $1.06 \times 10^{-1}$ & $3.16 \times 10^{-2}$ \\
$90^{\circ}$ & $2.65 \times 10^{-2}$ & $2.48 \times 10^{-3}$ \\
$180^{\circ}$ & $1.51 \times 10^{-2}$ & $8.38 \times 10^{-4}$ \\
\hline
\end{tabular}

These factors would be the same in iron, which is close to $\mathrm{Cu}$ in $\mathrm{Z}$ number, and 0.6 times lower in lead or tungsten. The unshielded dose rates for the three relevant angles are shown in Table 1.

Table 1. Unshielded Dose Rates at $1 \mathrm{~m}$ for Steel Components for $700 \mathrm{MeV}$ Operation at $1000 \mathrm{~W}$

\begin{tabular}{ccccc}
\hline \multirow{2}{*}{$\begin{array}{c}\text { STEEL } \\
\text { Angle, deg. }\end{array}$} & BREMS. & GRN & MEN & HEN \\
\cline { 2 - 5 } & \multicolumn{4}{c}{ (mrem/h at $1 \mathrm{~m})$} \\
\hline $0^{\circ}$ & $4.52 \times 10^{10}$ & $1.19 \times 10^{6}$ & $3.82 \times 10^{5}$ & $1.14 \times 10^{5}$ \\
$90^{\circ}$ & $1.38 \times 10^{7}$ & $1.19 \times 10^{6}$ & $9.54 \times 10^{4}$ & $8.93 \times 10^{3}$ \\
$180^{\circ}$ & $2.08 \times 10^{6}$ & $1.19 \times 10^{6}$ & $5.44 \times 10^{4}$ & $3.02 \times 10^{3}$ \\
\hline
\end{tabular}

For those computations involving the synchrotron ring, the bremsstrahlung, medium energy, and high energy neutron component angular dependence was taken into account as the forward angle with respect to the positron beam direction varied. For these estimates the synchrotron ring was assumed to be a circle of radius $54 \mathrm{~m}$.

\section{Shielding Computations}

Shielding computations were based upon the following expression for the beam loss in a component:

$$
\dot{\mathrm{H}}_{\mathrm{Tot}}=\frac{\sum_{i} \dot{\mathrm{H}}_{\mathrm{i}} \prod_{i, j} \exp -\frac{\mathrm{d}_{j}}{\lambda_{\mathrm{ij}}}}{\mathrm{r}^{2}}
$$


where $\dot{\mathrm{H}}_{\text {Tot }}$ is in units of mrem/h, $\dot{\mathrm{H}}_{\mathrm{i}}$ is the appropriate dose rate conversion factor for the $\mathrm{i}^{\text {th }}$ radiation component, $r$ is the distance from source to dose point in $m, d_{j}$ is the shield thickness in $\mathrm{g} / \mathrm{cm}^{2}$ for the $\mathrm{j}^{\text {th }}$ shield, and $\lambda_{\mathrm{i}, \mathrm{j}}$ is the attenuation length of the $\mathrm{i}^{\text {th }}$ radiation component for the $\mathrm{j}^{\text {th }}$ shielding material in $\mathrm{g} / \mathrm{cm}^{2}$.

The shield design calculations for non-accident conditions were based upon the operating parameters for the safety envelope. Estimates of the dose rates for this case were then scaled down by the ratio of the respective powers to obtain the estimated dose rates or doses for the case of the normal operational mode. In any case in which the estimates are slightly greater than the DOE design guideline of $0.25 \mathrm{mrem} / \mathrm{h}$ (DOE 92), additional local shielding will be added to achieve the guideline if actual survey measurements confirm that such calculated dose rates may be realized.

\subsection{Attenuation Length of Shielding Materials}

Attenuation lengths for the various shielding materials were obtained from Swanson (SWA 79a) and Moe (MOE 91). The value of each of these parameters, for a monoenergetic source, is expected to be constant with depth of penetration if no secondary radiation is produced. For a spectrum of radiation, the energy composition changes with penetration and the initial tenth value layer (TVL) will often differ from the equilibrium value. Values chosen for the attenuation lengths are effective values (spectrum-averaged), measured for spectra encountered at similar electron machines. In the absence of values for the MEN component, the value for the HEN component was used in order to be conservative. The attenuation length for the HEN component in all shield materials, except for concrete which was obtained from the literature, was computed from

$$
\lambda=38.5 \mathrm{~A}^{0.3} \mathrm{~g} / \mathrm{cm}^{2},
$$

as given in ICRU Report 28 (ICR 78).

The attenuation lengths, in $\mathrm{g} / \mathrm{cm}^{2}$, used in the computations and the density of the various shielding materials are shown in Table 2.

\subsection{Component and Beam Shielding Material Data}

Table 3 contains a listing of parameters for the assumed component and beam shielding materials. These parameters are used in the calculations to estimate the $\mathrm{e}^{-} / \mathrm{e}^{+}$stopping ability and the expected attenuation of the shower radiation by various components and shielding materials in the longitudinal and transverse directions. 
Table 2. Attenuation Lengths of Shielding Materials

\begin{tabular}{lcccc}
\hline \multirow{2}{*}{ MATERIAL (density-g/cm ${ }^{3}$ ) } & BREMS & GRN & MEN & HEN \\
\cline { 2 - 5 } & \multicolumn{4}{c}{$\lambda\left(\mathrm{g} / \mathrm{cm}^{2}\right)$} \\
\hline Concrete (2.35) & 49 & 40 & 65 & 115 \\
Concrete Block (2.08) & 49 & 40 & 65 & 115 \\
Pb (11.35) & 24 & 161 & 191 & 191 \\
Polyethylene (0.93) & 70 & 6.3 & 62 & 62 \\
Fe (7.87) & 34 & 100 & 138 & 138 \\
W (densalloy 18.0) & 26.3 & 161 & 184 & 184 \\
Earth (compacted 1.9) & 70 & 33 & 52 & 90 \\
Aluminum (2.7) & 46.5 & 40 & 104 & 104 \\
\hline
\end{tabular}

The critical energy, $E_{c}$, the minimum attenuation length for bremsstrahlung, $\lambda_{m}$, and radiation length, $X_{o}$, values were obtained from Swanson (SWA 79a). The Moliere radius, $X_{m}$, is related to the transverse development of the shower in a given material. The fraction of energy that escapes cylindrical volumes of a given radius can be estimated from the Moliere radius, according to Nelson (NEL 66). When the radius of the cylinder equals 1 Moliere unit, the fraction of energy that escapes is $\sim 0.1$. One may estimate the fraction of energy escaping through the side of the cylinder of radius, $\mathrm{R}$, using an expression from Swanson (SWA 87):

$$
\text { Fraction }=0.8 \mathrm{e}^{-3.45 \mathrm{R} / \mathrm{X}_{\mathrm{m}}}+0.2 \mathrm{e}^{-0.889 \mathrm{R} / \mathrm{X}_{\mathrm{m}}},
$$

where $\mathrm{R}$ and $\mathrm{X}_{\mathrm{m}}$ are expressed in the same units. The Moliere radius is related to the radiation length and the critical energy by the expression from ICRU Report 28 (ICR 78):

$$
\mathrm{X}_{\mathrm{m}}=\mathrm{X}_{\mathrm{o}} \frac{21.2}{\mathrm{E}_{\mathrm{c}}}
$$

where $E_{c}$ is in $\mathrm{MeV}$ and $\mathrm{X}_{\mathrm{m}}$ is in the same units as $\mathrm{X}_{\mathrm{o}}$.

\subsection{Shielding Approach}

The critical energy represents that energy at which the loss of energy per unit path ( $\mathrm{cm}$ or $\mathrm{g} / \mathrm{cm}^{2}$ ) of a given material is equal for both radiation production through the bremsstrahlung process and collision loss. Above the critical energy, more energy is lost to radiation formation (bremsstrahlung) than in the collision processes. The electromagnetic shower is not expected to develop sig- 
nificantly unless the electron energy is well above the critical energy in the given material. When the electron energy is high enough for the shower to develop significantly, the number of particles, photons, and/or electrons and positrons will initially increase with absorber thickness, reaching a maximum value at a thickness, $t$, given roughly by Bathow, et al. (BAT 67):

$$
t \sim X_{o} \ln E / E_{c} \text {, }
$$

where $E$ is the initial electron energy, and then be attenuated by the medium with an attenuation length that eventually is expressed by $\lambda_{\mathrm{m}}$. As the initial energy of the electron goes to higher and higher values, the attenuation of the electron becomes quite complex.

In the electromagnetic shower process electrons produce photons of high enough energy so that, when pair production occurs, the secondary electrons and positrons also have high enough energy to have long ranges in the material. In this situation the radiation length becomes the important parameter since it gives the thickness in which the electron loses $1 / \mathrm{e}$ of its energy to photon production. For high enough initial electron energy, several radiation lengths will be required before the particles in the shower reach a maximum value and begin to be attenuated. So, the amount of shielding needed will be more than just the range of the initial electrons of a given energy.

For lower-Z materials and not too high initial electron energy, the critical energy is high enough ( $51 \mathrm{MeV}$ for $\mathrm{Al}$ ) so that shower development is not too extensive. In high- $\mathrm{Z}$ materials, such as $\mathrm{W}$ and $\mathrm{Pb}$, the critical energies are low enough (see Table 3) for extensive shower development even at fairly low electron energy. To stop the beam for a low-energy electron source, high- $Z$ materials are more efficient and require less thickness, but the photon radiation will be higher than that in low- $Z$ materials and, as indicated in Equation (3), the giant resonance neutron production will be higher. The strategy then is to use low- $Z$ material to attenuate low-energy electron beams in order to avoid significant shower development with the increased giant resonance neutron production, if possible, and to use local supplemental shielding $(\mathrm{Pb}$ and/or polyethylene) in order to attenuate the secondary radiations adequately. As the energy of the electron or positron increases, low- $Z$ materials require too large a thickness to adequately stop the beam so that high- $\mathrm{Z}$ materials are used. For the higher energy electron beams, the production of higher energy neutrons (MEN and HEN) is less in high- $Z$ materials than in low- $Z$ materials, so high- $Z$ beam stops are more desirable, especially where space is a concern. 
Table 3. Component and Beam Shielding Material Data

\begin{tabular}{|c|c|c|c|c|c|c|}
\hline Mat'1 & $\mathrm{Z}$ & $\begin{array}{l}\text { Density } \\
\mathrm{g} / \mathrm{cm}^{3}\end{array}$ & $\begin{array}{c}\mathrm{E}_{\mathrm{c}} \\
\text { Critical } \\
\text { Energy } \\
\mathrm{MeV}\end{array}$ & $\begin{array}{c}\lambda_{\mathrm{m}} \\
\text { Attenuation } \\
\text { Length } \\
\mathrm{g} / \mathrm{cm}^{2}\end{array}$ & $\begin{array}{c}\mathrm{X}_{\mathrm{o}} \\
\text { Radiation } \\
\text { Length } \\
\mathrm{g} / \mathrm{cm}^{2}\end{array}$ & $\begin{array}{c}X_{\mathrm{m}} \\
\text { Moliere } \\
\text { Radius } \\
\mathrm{g} / \mathrm{cm}^{2}\end{array}$ \\
\hline $\mathrm{Al}$ & 13 & 2.7 & 51 & 46.5 & 24.0 & 10.0 \\
\hline $\mathrm{Fe}$ & 26 & 7.87 & 27.4 & 34.0 & 13.84 & 10.7 \\
\hline $\mathrm{Cu}$ & 29 & 8.96 & 24.8 & 33.0 & 12.86 & 11.0 \\
\hline W & 74 & 19.3 & 10.2 & 24.0 & 6.76 & 14.0 \\
\hline $\mathrm{Pb}$ & 82 & 11.35 & 9.51 & 24.0 & 6.37 & 14.2 \\
\hline Conc. & 11.6 & 2.35 & 51 & 49.0 & 25.71 & 10.7 \\
\hline
\end{tabular}

Note - Densalloy is about $95 \% \mathrm{~W}$ and has a density of $18 \mathrm{~g} / \mathrm{cc}$, for values of range, critical energy, radiation length and Moliere radius for densalloy, the values for $\mathrm{W}$ were used.

\subsection{Shielding Composition and Placement}

There are a number of regions of potential beam loss throughout the LEUTL system during operation. Losses may occur along the linac line during acceleration and transport, in the PAR bypass line or at the double beam stop, in the LEUTL line passing through the synchrotron or in the synchrotron beam stop, in the LEUTL line in the LEUTL tunnel, at the transition piece between the LEUTL vacuum pipe and the undulator vacuum chamber, or at the beam stop in the LEUTL. The shielding in the linac consists of $2 \mathrm{~m}$ of ordinary concrete on the Klystron gallery side and the dose point is about $6 \mathrm{~m}$ away from the line. The roof and other side of the linac tunnel are shielded by concrete and an earth berm giving, at least, the equivalent shielding ability of the $2 \mathrm{~m}$ of concrete. The highest dose rate during operation would be expected for losses in the linac line when the electrons have been fully accelerated to $700 \mathrm{MeV}$. The shielding of the PAR was discussed in MOE 93b, and is not significantly altered with the addition of the LEUTL bypass line. However, in place of a fixed beam stop just after the bending magnet that sends positrons into the PAR, the LEUTL bypass line includes a double stop. It consists of two W safety stops, each $7.62 \mathrm{~cm}$ thick, that will both be in a closed position when beam is not to be transported along the bypass line. These stops are not supposed to see any beam. If beam does hit them, they will shut down the linac. Either one of these stops is sufficient to insure that the dose rate in the forward direction on the synchrotron side of the shielding wall will not be excessive, if the beam should accidently strike the stop. The PAR bypass line also contains a Pb shield that insures that there is no line-ofsight path from PAR components through the LEUTL beampipe into the synchrotron.

In the synchrotron the beam may be sent to the beam stop (Figure 3). The stop consists of a watercooled aluminum block ( $15.24 \mathrm{~cm} \times 15.24 \mathrm{~cm} \times 20.32 \mathrm{~cm}$ thick) surrounded by $\mathrm{Pb}$ and polyethylene. Additional shielding is provided by the 1.5 - $\mathrm{m}$-thick normal concrete wall of the synchrotron 
and an added $45.72 \mathrm{~cm}$ of stacked concrete blocks along a 5.5-m section of the wall adjacent to the beam stop, where the shortest dose point distance is about $3.9 \mathrm{~m}$. The stop itself provides $20.32 \mathrm{~cm}$ of $\mathrm{Pb}$ equivalent shielding on the Building 412 side and $10.16 \mathrm{~cm}$ of $\mathrm{Pb}$ equivalent on the infield side. The roof of the synchrotron provides only $1 \mathrm{~m}$ of concrete, so the top of the beam stop consists of $30.48 \mathrm{~cm}$ of $\mathrm{Pb}$, backed up by $15.24 \mathrm{~cm}$ of polyethylene. The $\mathrm{Pb}$ equivalent shielding in the beam direction is $30.48 \mathrm{~cm}$ of $\mathrm{Pb}$. If the beam is sent on to the LEUTL tunnel, it is bent upward by SV1 (see Figure 3) at about a 25-mradian angle for $40 \mathrm{~m}$, and reaches a height of $2.4 \mathrm{~m}$ in the synchrotron tunnel. Then it is bent back parallel to the original direction of the electron beam and sent into the alcove between the synchrotron tunnel and the LEUTL tunnel. A W stop $(7.62 \mathrm{~cm})$ is placed in the LEUTL line after the beam enters the alcove. This stop will be closed when work is being conducted in the LEUTL tunnel to ensure that if beam errantly arrives at bending magnet SV2 (see Figure 3) when it is off, producing a shower in this magnet, the radiation that travels down the LEUTL beam pipe will be significantly attenuated. In being transported through the synchrotron, a portion of the beam could be lost along the beamline, causing a radiation dose rate on the mezzanine of the synchrotron. Since the height of the synchrotron tunnel is $2.743 \mathrm{~m}$, the LEUTL line eventually is only $0.343 \mathrm{~m}$ below the ceiling of the synchrotron. A loss of beam in this higher section of the line will lead to the highest dose rate on the synchrotron mezzanine.

The alcove region and the LEUTL tunnel are both part of the bermed shielding for the LEUTL (see Figure 1), and access to these regions is restricted by the steel fencing. Losses may occur along the length of the LEUTL line in the alcove or the LEUTL tunnel. Failure of the permanent magnet to bend the electron beam into the beam dump near the end of the LEUTL will result in the particle beam striking the $\mathrm{Pb}$ shield at the end of the LEUTL line. The wall at the east end of the LEUTL tunnel is concrete (1.219 $\mathrm{m}$ thick), and the concrete sections of the access maze are each $0.914 \mathrm{~m}$ thick. The tunnel walls are concrete $(30.48 \mathrm{~cm}$ thick), covered by an earth berm $(\rho=$ $1.9 \mathrm{~g} / \mathrm{cc}$ ) of slope about $22.5^{\circ}$, which gives an earth shielding thickness of $6.63 \mathrm{~m}$ at beam height $(1.4 \mathrm{~m})$. The $1.83 \mathrm{~m}$ steel fence limits access to the bermed area so that the distance. of closest approach on the south side of the berm is $10 \mathrm{~m}$ from the tunnel wall, and about $9 \mathrm{~m}$ for the north side of the berm. The roof of the tunnel is concrete ( $38.1 \mathrm{~cm}$ thick), covered by $1 \mathrm{~m}$ of earth berm and $15.24 \mathrm{~cm}$ of top soil. The access maze consists of two fixed concrete walls and a movable section made out of stacked concrete blocks between the two fixed walls. The movable wall extends outward between the other walls to insure that scattered radiation must undergo at least two scattering interactions before being able to get out of the maze. The $\mathrm{Pb}$ beam stop in front of the first fixed concrete wall is $17.78 \mathrm{~cm}$ thick in the beam direction and $10.16 \mathrm{~cm}$ thick in all transverse directions. The electron beam stop is similar to the stop used in the synchrotron to catch beam after it leaves the PAR.

\section{Estimated Radiation Dose Rates at Safety Envelope Operation}

\subsection{Loss Estimate for a Beam Spill}

The LEUTL beamline represents a long-running straight portion of beamline starting in the linac. When losses occur, an electromagnetic shower is produced that represents an extended source of radiation or spill that can be treated as a line source. A spill results in the radiation being emitted 
along a line source toward the dose point, as the particles strike an accelerator component and initiate an electromagnetic shower. As shown in the following sketch, radiation from each differential element, $\mathrm{dl}$, contributes to the total dose rate at the dose point, $\mathrm{P}$, after passing through two different shield materials of thickness $t_{1}$ and $t_{2}$, respectively:

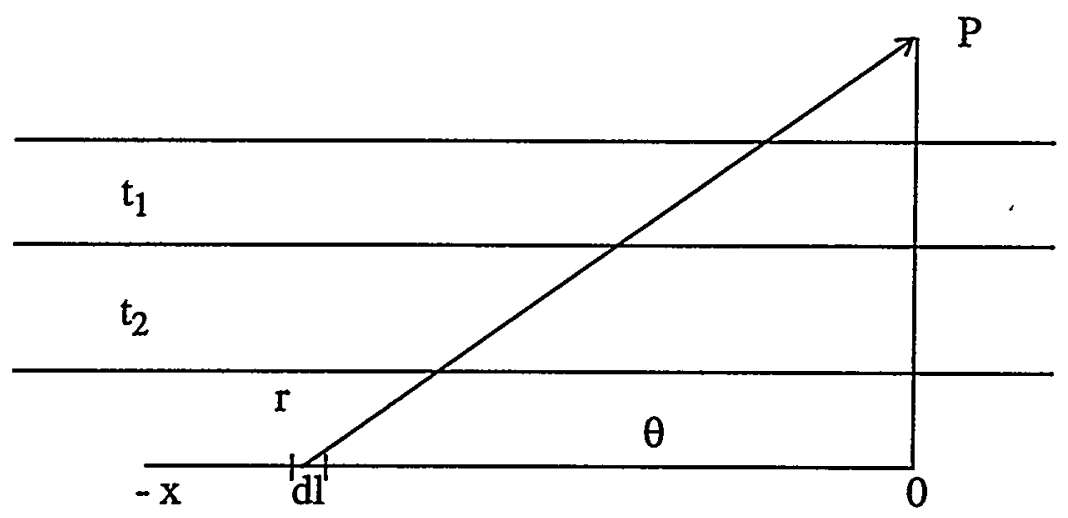

The dose rate $(\mathrm{mrem} / \mathrm{h})$ at the point $\mathrm{P}$ from the differential line segment $\mathrm{dl}$ for the ith radiation component can be expressed as

$$
\mathrm{dH}_{\mathrm{i}}=\left[3600 P F_{i} \prod_{i, j} \exp -t^{-t_{j} /(\sin \theta) \lambda_{i, j}}\right] \frac{\mathrm{dl}}{\mathrm{r}(\theta)^{2}}
$$

where $P$ is the power lost per $m$ of length (W/m), $3600 \mathrm{~s} / \mathrm{h}$ converts $W$ to $\mathrm{J} / \mathrm{h}, F_{i}$ is the dose constant $(\mathrm{mrem} / \mathrm{J}$ at $1 \mathrm{~m})$ for the ith radiation component, $\mathrm{t}_{\mathrm{j}}$ is the straight through thickness of the $j$ th shield material in $\mathrm{g} / \mathrm{cm}^{2}, \lambda_{\mathrm{i}, \mathrm{j}}$ is the attenuation length of the ith radiation component for the $\mathrm{jth}$ shield material in $\mathrm{g} / \mathrm{cm}^{2}, \mathrm{r}(\theta)$ is the distance $(\mathrm{m})$ from the differential line segment to the dose point $P$, and $\theta$ is the angle between the line segment and the dose point. The total dose rate contribution $(\mathrm{mrem} / \mathrm{h})$ at the point $\mathrm{P}$ is found by integrating over the length of the line segment:

$$
\dot{\mathrm{H}}_{\mathrm{i}}=3600 \mathrm{P} \sum_{\mathrm{i}} \int_{-\mathrm{x}}^{0} \frac{\mathrm{F}_{\mathrm{i}} \prod_{i, j} \exp ^{-\mathrm{t}_{\mathrm{j}} /(\sin \theta) \lambda_{i, j}}}{\mathrm{r}(\theta)^{2}} \mathrm{dl} .
$$

Equations (9) and (10) were used for the evaluation of dose rates on the sides and top of the tunnels and also for other loss locations where the angular distribution of dose was of interest. Based upon the empirical results obtained during missteering studies at the storage ring of the APS (DEC 97), a spill length of $4 \mathrm{~m}$ was used in the estimates of dose rates. This assumed spill length was shown to give conservative results by at least a factor of 3 in comparing calculated results with the measurements. 


\subsubsection{Beam Spill in the Linac}

The general layout of the linac and klystron gallery is shown in Figure 4. See Appendix B for the location of an $\mathrm{rf}$ and laser room at the gun end of the linac. The dose point is taken to be $6 \mathrm{~m}$ away from the beamline in the klystron gallery. If a spill occurs in the LEUTL line, the highest dose rate would be expected when the maximum energy of the electron is reached. For this situation, the beam power at the safety envelope will be $1000 \mathrm{~W}$, and the spill loss rate will be $250 \mathrm{~W} / \mathrm{m}$. Assuming a thickness of $0.16 \mathrm{~cm}$ for the stainless steel beampipe and $2 \mathrm{~m}$ of concrete shielding, the dose rate in the gallery would be $27.3 \mathrm{mrem} / \mathrm{h}$. The concrete roof is $30.5 \mathrm{~cm}$ thick and covered by a 3-m-thick earth berm to give the shielding equivalent of $2 \mathrm{~m}$ of concrete. The entire bermed region is enclosed by a fence making it an exclusion zone. The dose rate through the roof for a spill is $24.3 \mathrm{mrem} / \mathrm{h}$. The dose rate through the bermed side of the linac at the fenceline would be $5 \mathrm{mrem} / \mathrm{h}$.

\subsubsection{Beam Spill in the PAR}

In leaving the linac, the LEUTL beamline passes directly under a $30.5-\mathrm{cm}$ concrete roof covered with $3.56 \mathrm{~m}$ of earth berm. The dose point is above the berm $6.2 \mathrm{~m}$ away and the dose rate during the spill duration is $4.3 \mathrm{mrem} / \mathrm{h}$. As the beamline passes through the PAR region (see Figure 2), a spill could occur that would produce a dose rate on the PAR mezzanine or in the synchrotron. The parameters for the PAR mezzanine are: distance to dose point, $3.67 \mathrm{~m}$; concrete shield thickness, $1.075 \mathrm{~m}$; earth shield thickness, $39 \mathrm{~cm}$; and steel thickness, $0.16 \mathrm{~cm}$. For a 4-m spill along this region, the dose rate is $1.58 \mathrm{rem} / \mathrm{h}$. Further along in the PAR, the line passes under the connecting corridor and into the shielding between the PAR and the synchrotron. If a spill occurs in the 4-mlong region just before the beam enters the additional shielding (region $A$ in Figure 2), the dose point distance is $3.342 \mathrm{~m}$ and the shielding is only $1 \mathrm{~m}$ of concrete. In this instance, the dose rate is $7.34 \mathrm{rem} / \mathrm{h}$ in the connecting corridor above. The dose rate in the synchrotron is not relevant for this spill since personnel are excluded from the synchrotron tunnel during LEUTL operations.

\subsubsection{Beam Spill in the Synchrotron}

After the beam passes through the shielding wall between the PAR and the synchrotron, it is bent upward at an angle of 25 mradians for about $40 \mathrm{~m}$, reaching a height of $2.7 \mathrm{~m}$ in the synchrotron tunnel. At this point the beam is bent back parallel to the original beamline and sent into the alcove (see Figure 3). A spill almost anywhere along this line will produce dose rates in Building 412 and on the mezzanine area above the synchrotron. The elevation in the line affects the dose rate on the mezzanine. With respect to Building 412 , the LEUTL line is $3.4 \mathrm{~m}$ from the dose point, the shielding is $1.5 \mathrm{~m}$ of normal concrete, and the dose rate is $684 \mathrm{mrem} / \mathrm{h}$.

With respect to the mezzanine, the beam reaches the bend point (SV2) in a bermed region of the synchrotron tunnel, which is past the end of the mezzanine area. For the highest dose rate in the mezzanine area, the beam must spill in the region B of Figure 3, which is a seldom occupied area. The average beam height in this region is about $2.3 \mathrm{~m}$, so the distance to the dose point is $2.443 \mathrm{~m}$ and the shielding is $1 \mathrm{~m}$ of concrete. The dose rate for this case is $13.1 \mathrm{rem} / \mathrm{h}$. If the beam spills in 
Figure 4. Layout of the linac showing $6 \mathrm{~m}$ line in the klystron gallery.

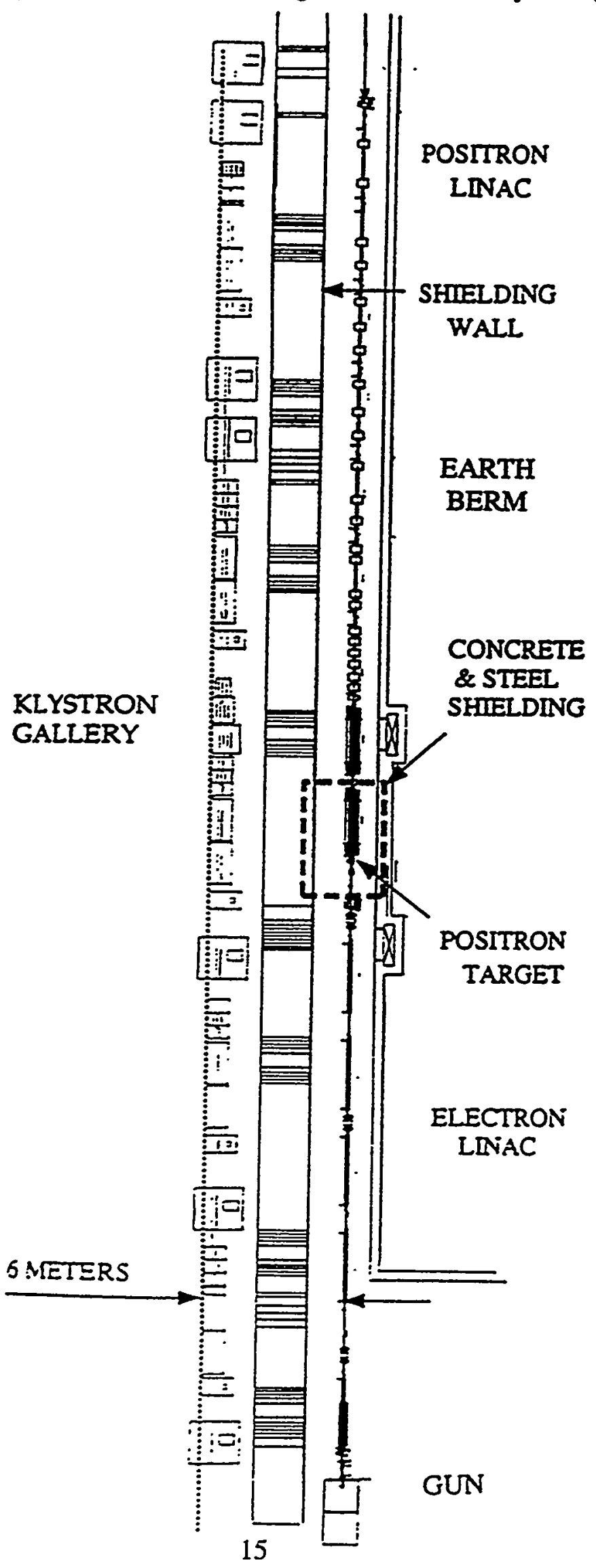


a region that is not elevated, the distance to the dose point is $3.343 \mathrm{~m}$ and the dose rate is 8.2 $\mathrm{rem} / \mathrm{h}$. Combining these results, the average dose rate for this spill is $10.7 \mathrm{rem} / \mathrm{h}$.

\subsubsection{Beam Spill in the LEUTL Tunnel}

For a beam spill in the alcove or LEUTL tunnel, the parameters for the south side are: $13.043 \mathrm{~m}$ to the dose point, $6.63 \mathrm{~m}$ of earth at beam height, plus $30.5 \mathrm{~cm}$ of concrete. The dose rate is 0.3 $\mu \mathrm{rem} / \mathrm{h}$. For the north side, the distance to the dose point is $9.324 \mathrm{~m}$, the earth berm is $6.63 \mathrm{~m}$ thick, and the wall is $30.5 \mathrm{~cm}$ of concrete. The dose rate during the spill is $0.52 \mu \mathrm{rem} / \mathrm{h}$. For the roof, which is within the fenced-in area, the parameters are: $3.874 \mathrm{~m}$ to the dose point, $1.15 \mathrm{~m}$ of earth berm, and $38.1 \mathrm{~cm}$ of concrete shielding. The dose rate is $5.23 \mathrm{rem} / \mathrm{h}$.

\subsection{Dose Rates for Beam Stops}

There are four beam stops in the LEUTL system. Two of these, the double stop in the PAR (Figure 2) and the stop at the end of the LEUTL line in the LEUTL tunnel (Figure 1), are designed to take beam only if a failure occurs. The double stop in the PAR will stop an electron beam being sent on through the LEUTL line when it isn't supposed to be. Similarly, a failure of the permanent magnet in the LEUTL allows electrons to strike a beam stop at the end of the LEUTL instead of the particle beam dump. The other two, the booster beam dump and the particle beam dump in the LEUTL tunnel, have been designed to routinely handle the particle beam.

\subsubsection{Dose Rates from the PAR Double Stop}

The PAR double stop consists of two W stops, each $7.62 \mathrm{~cm}$ thick and $10.16 \mathrm{~cm}$ on a side. The dose estimates were calculated assuming only one stop is in place. Assuming a 1-kW beam of $700-\mathrm{MeV}$ electrons is inadvertently sent on to the double beam stop, the distribution of dose rate with angle relative to the incident direction of the electron beam is shown for the synchrotron and Buildings 411 and 412 in Figure 5. Near the points marked $P$ are shown dose rates $(\mathrm{mrem} / \mathrm{h})$ in the. synchrotron at the angle given by the subscript of the $\mathrm{P}$ value. The points marked $\mathrm{Q}$ show corresponding dose rates in Buildings 411 and 412, again with the subscript indicating the angle with respect to the original direction of the electron beam. Directly above the double stop is the bermed area of the PAR-Linac tunnel, and the dose rate above the berm region is $0.18 \mathrm{mrem} / \mathrm{h}$. Using the same parameters for the PAR mezzanine as in section 5.1.2, the dose rate on the PAR mezzanine would be $82.8 \mathrm{mrem} / \mathrm{h}$.

\subsubsection{Dose Rates from the Synchrotron Beam Dump}

Figure 3 shows the location of the LEUTL beam stop in the synchrotron and the additional concrete blocks in the vicinity of the stop for added shielding ability. The block wall is normal concrete, $46 \mathrm{~cm}$ thick, about $5.5 \mathrm{~m}$ in length and $2.29 \mathrm{~m}$ high. The stop is $3.86 \mathrm{~m}$ from the dose point, and the total concrete shielding is $1.96 \mathrm{~m}$ thick. The beam stop itself consists of a water-cooled aluminum block ( $15.24 \mathrm{~cm} \times 15.24 \mathrm{~cm} \times 20.32 \mathrm{~cm}$ thick), surrounded by lead. On the Building 412 side, the shield is $7.62 \mathrm{~cm}$ of $\mathrm{Al}$ and $20.32 \mathrm{~cm}$ of $\mathrm{Pb}$. There is $10.16 \mathrm{~cm}$ of $\mathrm{Pb}$ on the infield side and bottom of the shield, and $30.48 \mathrm{~cm}$ of $\mathrm{Pb}$ and $15 \mathrm{~cm}$ of polyethylene on the top of the beam stop. The highest dose rate in Building 412, through the added concrete blocks, is 2.6 
Figure 5. Dose rate distribution in the synchrotron, Buildings 411 and 412 , from a 1-kW electron beam ( $700 \mathrm{MeV})$ striking the double stop.

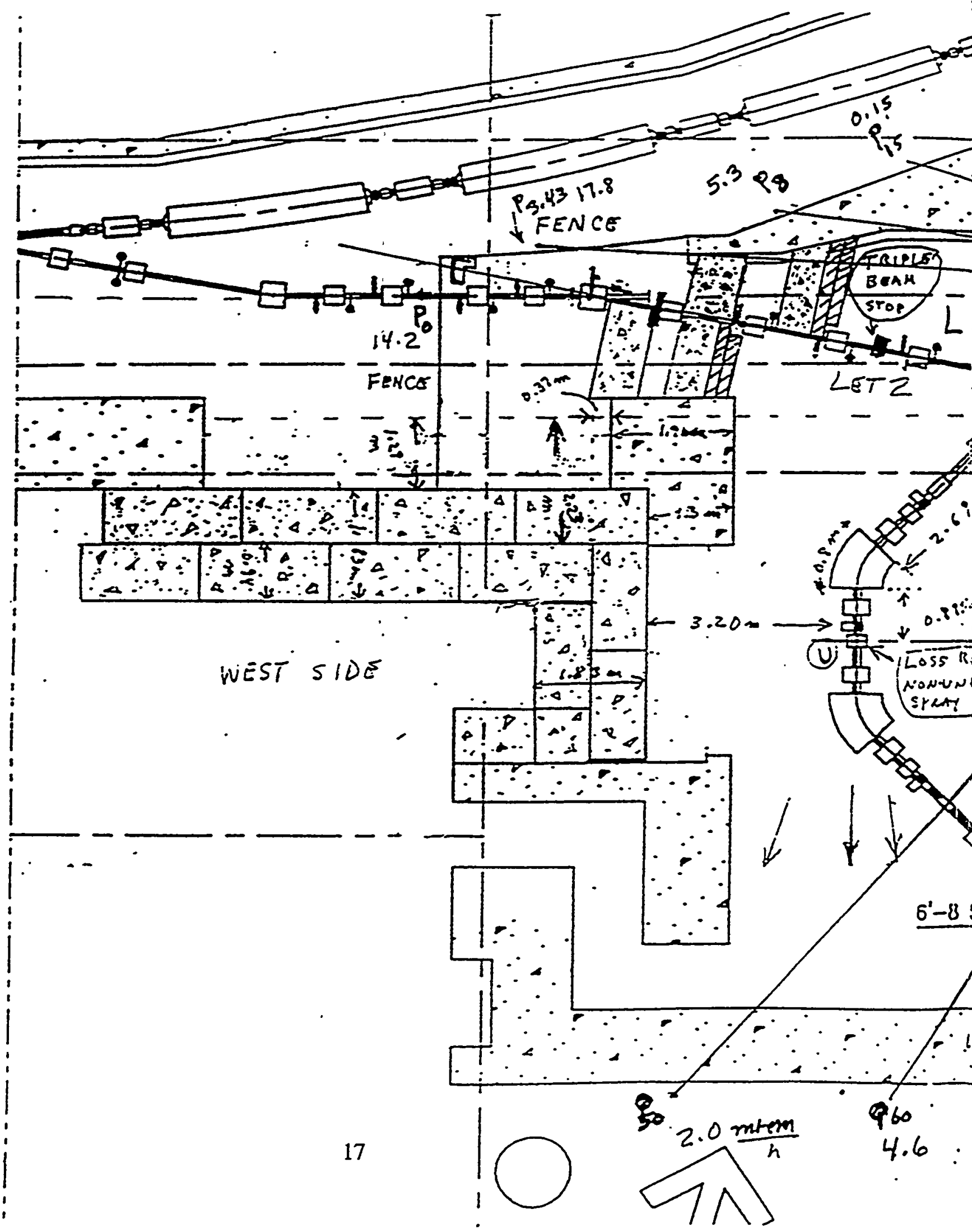




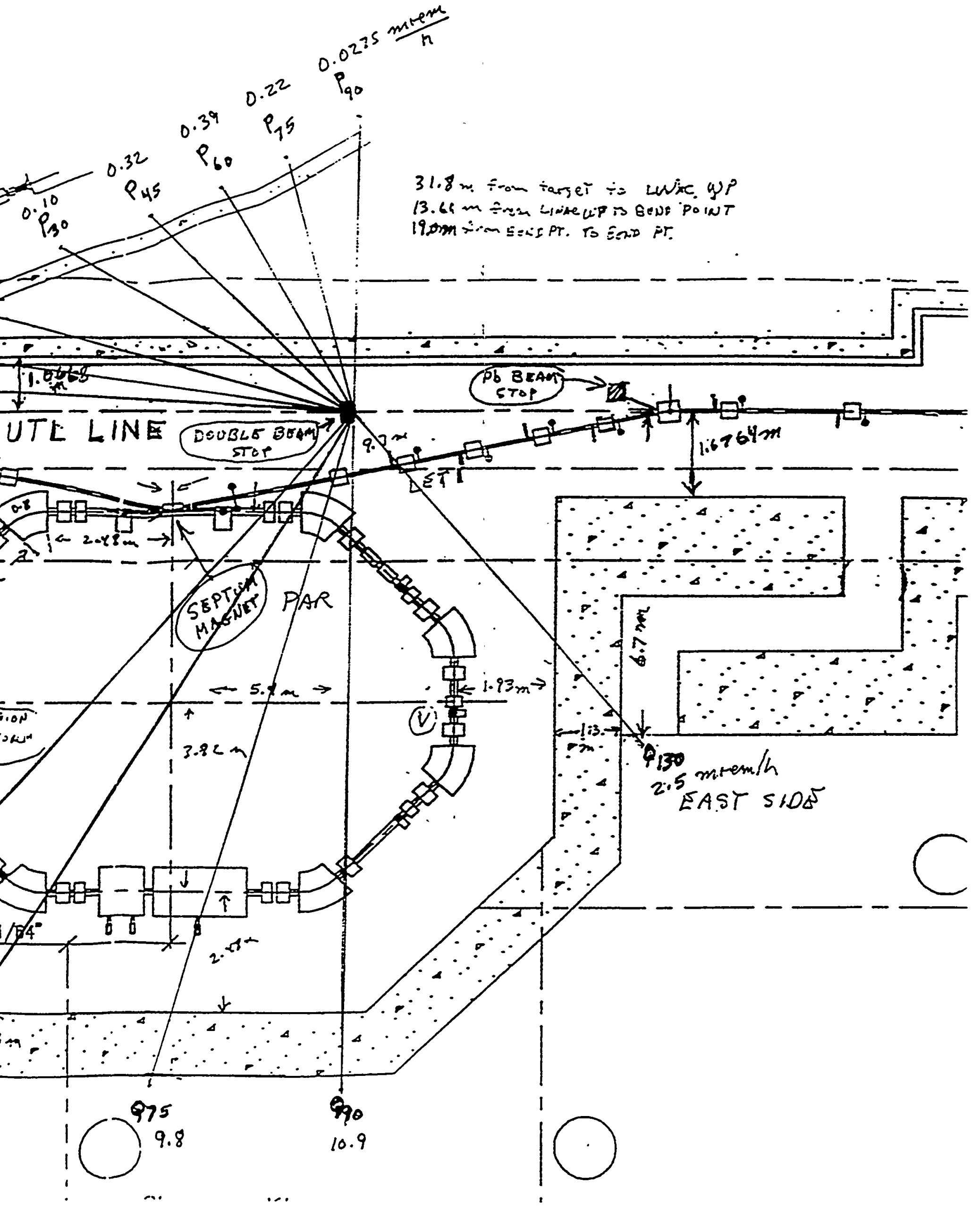


$\mathrm{mrem} / \mathrm{h}$ at the safety envelope. The highest dose rate directly above the dump on the synchrotron mezzanine is $10.7 \mathrm{mrem} / \mathrm{h}$. Additional shielding will need to be added if this region, normally an unoccupied area, will need to be occupied during operation of the LEUTL at or near the safety envelope power. This will be checked by survey measurements at a lower power level and additional shielding will be added, if appropriate.

\subsubsection{Dose Rates for the LEUTL Beam Stops}

The particle beam stop in the LEUTL tunnel is located by the north wall of the tunnel (see Figure 1). It utilizes the bermed and fenced-in area on that side of the tunnel. The particle beam is bent by a permanent magnet into the stop. The stop has $20.32 \mathrm{~cm}$ of $\mathrm{Al}$ and $30.48 \mathrm{~cm}$ of $\mathrm{Pb}$ in the forward direction and $7.62 \mathrm{~cm}$ of $\mathrm{Al}$ and $20.32 \mathrm{~cm}$ of $\mathrm{Pb}$ in the direction of the end station, backed up by the berm and exclusion fence. At beam height, the thickness of the berm is $6.63 \mathrm{~m}$ and the distance to the dose point is $7.8 \mathrm{~m}$. The dose rate at safety envelope operation is $0.3 \mu \mathrm{rem} / \mathrm{h}$. The highest dose rate in the end station at safety envelope operation was outside of the maze doorway. This was $0.9 \mathrm{mrem} / \mathrm{h}$. The dose rates for other points were all negligible.

In case of failure of the electro-magnet to bend the particle beam into the beam stop, the particle beam will proceed into the $\mathrm{Pb}$ stop in front of the concrete maze wall. The stop is $25.4 \mathrm{~cm} \times 25.4$ $\mathrm{cm} \times 27.94 \mathrm{~cm}$ thick. The beam enters the stop through a $5.08 \mathrm{~cm} \times 5.08 \mathrm{~cm}$ opening in the $\mathrm{Pb}$ block and strikes the $17.78 \mathrm{~cm} \mathrm{~Pb}$ shield in the forward direction. This shield is backed up by the two concrete maze walls that are each $91.44 \mathrm{~cm}$ thick and $2.743 \mathrm{~m}$ apart (Figure 1). The amount of $\mathrm{Pb}$ on the sides and top of the beam stop of the beam varies from $10.16 \mathrm{~cm}$ to $15.24 \mathrm{~cm}$. The dose rate in the end station for operation at the safety envelope is $105 \mathrm{mrem} / \mathrm{h}$. The dose rate outside of the north side fence of the tunnel is $0.3 \mathrm{mrem} / \mathrm{h}$, and that outside of the south side fence is $0.1 \mathrm{mrem} / \mathrm{h}$.

\subsection{Dose Rates for Continuous Loss During Beam Transport}

During transport of the beam, a certain amount of beam is lost along the beamline. Collisions with gas molecules lead to energy loss which results in particles being lost from the beam and striking the accelerator components. Assuming a constant particle loss of $1 \times 10^{-4} / \mathrm{m}$ should give a conservative estimate of the expected dose rates during the particular operating conditions. For each system, an infinite line source is assumed that will give an overestimate of the dose rate for each system. An additional conservatism is that no credit is taken for absorption of radiation by the magnets and other components in the beamline. Regardless of the computational results, the actual dose rates will be determined during the commissioning phase and appropriate remedial action will be taken for unacceptably high dose rates. For safety envelope operation, the power loss rate along the LEUTL beamline is $0.1 \mathrm{~W} / \mathrm{m}$, except in the accelerating portion of the linac, where the loss rate is lower.

\subsubsection{Continuous Loss in the Linac}

The power loss will be variable in the linac since the energy is changing as the particle beam is being accelerated. The highest dose rate would occur when the beam has reached its highest energy $(700 \mathrm{MeV})$, which is at the end of the linac. Using the same linac parameters as in 5.1.1 
and a loss rate of $0.1 \mathrm{~W} / \mathrm{m}$, the dose rate in the klystron gallery is $0.018 \mathrm{mrem} / \mathrm{h}$. The dose rate on the roof is $0.014 \mathrm{mrem} / \mathrm{h}$, and that on the bermed side of the linac is $0.0057 \mathrm{mrem} / \mathrm{h}$.

\subsubsection{Continuous Loss in the PAR}

Utilizing the same PAR parameters as in section 5.1.2 and a loss rate of $0.1 \mathrm{~W} / \mathrm{m}$, the dose rate on the PAR mezzanine is $0.81 \mathrm{mrem} / \mathrm{h}$. The dose rate above the bermed area is $3 \mu \mathrm{rem} / \mathrm{h}$, and that in the connecting corridor is $3.1 \mathrm{mrem} / \mathrm{h}$.

\subsubsection{Continuous Loss in the Synchrotron}

The parameters for the synchrotron were given in section 5.1.3. The dose rate in Building 412 for a $0.1 \mathrm{~W} / \mathrm{m}$ loss rate is $0.33 \mathrm{mrem} / \mathrm{h}$. The average dose rate on the synchrotron mezzanine is 5.2 $\mathrm{mrem} / \mathrm{h}$.

\subsubsection{Continuous Loss in the LEUTL Tunnel}

For a loss rate of $0.1 \mathrm{~W} / \mathrm{m}$ in the LEUTL tunnel, using the parameters of section 5.1.4, the dose rates on the north and south sides of the tunnel are negligible. The dose rate on the bermed roof is $3 \mathrm{mrem} / \mathrm{h}$.

\subsection{Dose Rates for Loss on Transition Piece of Undulator}

At the junction of the LEUTL beamline with an undulator, the chamber gap dimension changes from about $4 \mathrm{~cm}$ to about $1 \mathrm{~cm}$. This is accomplished through a transition piece made out of tungsten, containing a machined elliptical cone that has the desired tapered shape. The block is housed in a steel box. The tungsten block is about $18 \mathrm{~cm}$ in length and from 1.5 to $3.2 \mathrm{~cm}$ in thickness (2.4 $\mathrm{cm}$ average thickness is used in the calculations). From Table 3, the radiation length (RL) of $\mathrm{W}$ is $6.76 \mathrm{~g} / \mathrm{cm}^{2}$, which gives $0.35 \mathrm{~cm}$ for a density of $19.3 \mathrm{~g} / \mathrm{cc}$. Since the total length of the block is about $51 \mathrm{RL}$, the entire shower could develop in the block if the electron beam strikes the block at a sufficiently shallow angle. To be conservative, it is assumed that $20 \%$ of the beam is lost on the transition piece, and the full shower develops in the block. For operation at the LEUTL safety envelope, the power loss on the transition piece is $200 \mathrm{~W}$. The shielding and distance parameters for the LEUTL tunnel are as stated in section 5.1.4. The dose rates are: $0.3 \mu \mathrm{rem} / \mathrm{h}$ on the south side of the tunnel, $0.5 \mu \mathrm{rem} / \mathrm{h}$ on the north side, and $198 \mathrm{mrem} / \mathrm{h}$ on the roof.

\subsection{Estimate of Muon Contribution}

When the electron energy is above $1 \mathrm{GeV}$, the production rate of muons may become a problem, but generally only in the forward direction. Muons can be produced as pairs in electromagnetic interactions and by decay of pions (ICR 78). Muons are initially emitted in a narrow cone within a few units of the characteristic angle given by $105.66 / \mathrm{E}_{\mu}$ radians (TSA 74), in which $105.66 \mathrm{MeV}$ is the rest energy of the muon and $\mathrm{E}_{\mu}$ is the muon energy in $\mathrm{MeV}$. Some scattering occurs, but the major attenuation is by energy loss through ionization. So, muons have great penetrating power and require large thicknesses of material to attenuate them. The fluence rate of muons has been 
measured by Nelson (NEL 68) and this data can be adapted to dose rates as given in Swanson (SWA 79a). Using the graph in Swanson to obtain the fluence rate of muons $\left(3.1 \times 10^{5} \mu / \mathrm{cm}^{2} \mathrm{~s}\right)$ for $7.7 \mathrm{GeV} \mathrm{e} \mathrm{e}^{+}$and the dose rate constant of $7.23 \mu / \mathrm{cm}^{2} \mathrm{~s}=1 \mathrm{mrem} / \mathrm{h}$ obtained from ICRP Publication 51 (ICP 87), the unshielded dose rate constant for $7.7 \mathrm{GeV}$ muons was found to be 42.9 $\mathrm{rem} / \mathrm{kWh}$ at $1 \mathrm{~m}$ (MOE 94). In the case of the storage ring, the muon dose rate turned out to be negligible. Since the dose rate constant for $700 \mathrm{MeV}$ muons is about a factor of 25 less than that of $7.7 \mathrm{GeV}$ muons, they are not expected to be a problem for LEUTL operations.

\section{Dose Rates for Design Performance Goal Operating Mode}

As stated in section 2, the Design Performance Goal equates to a beam power of $120 \mathrm{~W}$ at the end of the linac. To determine dose rates for losses occurring at this power level, the previous results can be scaled by the factor $120 / 1000=0.12$. This will be conservative for the forward-directed radiation because these dose rates would be higher for a $700-\mathrm{MeV}$ beam than those for a 400 $\mathrm{MeV}$ beam.

For a beam spill in the linac, the corresponding dose rates for this operating mode would be: 3.3 $\mathrm{mrem} / \mathrm{h}$ in the klystron gallery, $2.9 \mathrm{mrem} / \mathrm{h}$ through the roof, and $0.6 \mathrm{mrem} / \mathrm{h}$ through the bermed side of the linac. The adjusted continuous power loss rate would be $1.2 \times 10^{-3} \mathrm{~W} / \mathrm{m}$, resulting in dose rates of $2.2 \mu \mathrm{rem} / \mathrm{h}$ in the klystron gallery, $1.7 \mu \mathrm{rem} / \mathrm{h}$ on the roof, and $0.7 \mu \mathrm{rem} / \mathrm{h}$ on the bermed side.

Dose rates in the PAR for a spill would scale to: $0.5 \mathrm{mrem} / \mathrm{h}$ above the bermed area, $190 \mathrm{mrem} / \mathrm{h}$ on the PAR mezzanine, and $881 \mathrm{mrem} / \mathrm{h}$ in the connecting corridor. The highest dose rate for beam into the double stop would be $9.9 \mathrm{mrem} / \mathrm{h}$ on the PAR mezzanine. The dose rates for continuous power loss are $0.097 \mathrm{mrem} / \mathrm{h}$ on the PAR mezzanine, negligible above the bermed area, and $0.37 \mathrm{mrem} / \mathrm{h}$ in the connecting corridor.

For spills along the LEUTL line in the synchrotron, the dose rates would range from $82 \mathrm{mrem} / \mathrm{h}$ in Building 412 to $1.57 \mathrm{rem} / \mathrm{h}$ on the synchrotron mezzanine. If the beam is sent into the synchrotron beam dump, the highest dose rate in Building 412 is $0.41 \mathrm{mrem} / \mathrm{h}$ and the dose rate on the synchrotron mezzanine is $1.6 \mathrm{mrem} / \mathrm{h}$. In the case of continuous loss, the dose rates are: $12 \mu \mathrm{rem} / \mathrm{h}$ in Building 412 and an average dose rate of $0.6 \mathrm{mrem} / \mathrm{h}$ on the synchrotron mezzanine.

The spill dose rates on the north and south sides of the LEUTL tunnel at the fences are negligible for Design Performance Goal operation. The dose rate on the bermed roof that is within the fenced area is $628 \mathrm{mrem} / \mathrm{h}$. For the particle beam stop, the highest dose rate is $0.1 \mathrm{mrem} / \mathrm{h}$ in the end station outside of the maze doorway. The highest dose rate in the end station if the particle beam hits the $\mathrm{Pb}$ stop at the end of the LEUTL line is $12.6 \mathrm{mrem} / \mathrm{h}$. For the continuous loss scenario, the dose rates on the north and south sides of the LEUTL tunnel are negligible. The dose rate on the bermed roof is $0.36 \mathrm{mrem} / \mathrm{h}$. 


\section{Synchrotron Radiation}

In general, synchrotron radiation losses are insignificant for linear accelerators (GOD 68). However, when electrons or positrons are bent in circular orbits, they radiate intense electromagnetic radiation (synchrotron radiation) in a highly peaked forward cone of radiation. Also, the alternating magnetic fields in an insertion device (ID) produce synchrotron radiation at great intensity by bending electrons along a sinusoidal path. In the LEUTL tunnel, synchrotron radiation is emitted as the particles go through the test insertion devices. The synchrotron radiation from the Ds proceeds directly forward down the beamline, but can be scattered by any component that it strikes. Little scattering is expected during transport of the synchrotron radiation. If the energy of the accelerated $e-$ is high enough, some of the synchrotron radiation may escape the steel vacuum chamber and irradiate the air in the tunnel, potentially causing radioactive and/or noxious gas production.

An undulator is an insertion device in which the radiation is concentrated in a number of narrow energy bands called the harmonics. These bands represent radiation from different periods of the magnet array that interfere constructively (ALS 89). The photon energy (keV) of the nth harmonic is given by (SHE 88):

$$
E_{n}=\frac{0.949 E_{R}^{2} n}{\lambda_{0}\left(1+\frac{K^{2}}{2}+\gamma^{2} \theta^{2}\right)},
$$

where $E_{R}$ is the electron energy $(\mathrm{GeV}), \lambda_{0}$ is the undulator period $(\mathrm{cm}), \mathrm{K}$ (called the deflection parameter) is a function of $\lambda_{0}$ and the peak magnetic field, $\theta$ is the off-axis angle (radians), and $\gamma$

$=\mathrm{E}_{\mathrm{R}} / 5.11 \times 10^{-4}$. Using parameters for an APS Type-A undulator $\left(\lambda_{0}=3.3 \mathrm{~cm}, \mathrm{~K}=2.464\right.$ and $\theta$ $=0$ ), the on-axis energy of the first harmonic for an energy of $700-\mathrm{MeV}$ electrons is about $35 \mathrm{eV}$. This energy photon will not penetrate the $0.16-\mathrm{cm}$ thickness of the stainless steel vacuum pipe. Even the higher harmonics are not energetic enough to penetrate the vacuum pipe. For example, the attenuation coefficient for a $1-\mathrm{keV}$ photon in stainless steel is estimated to be $8268 \mathrm{~cm}^{2} / \mathrm{g}$ (Type $304 \mathrm{SS}$ ). Assuming a density of $8 \mathrm{~g} / \mathrm{cc}$, the attenuation factor: $\mathrm{e}^{-(8268) 8(.16)}$ is $<1 \times 10^{-99}$ for $1 \mathrm{keV}$ photons and would be much smaller for $\mathrm{E}<1 \mathrm{keV}$. For this reason, no synchrotron radiation is expected to penetrate the vacuum chamber.

\section{Gas Bremsstrahlung}

The interaction of particles with the residual molecules of air in the vacuum chamber produces bremsstrahlung that can be a problem in the long straight section of the LEUTL. Since this bremsstrahlung radiation is produced in the straight section, the forward-peaked component will travel along with the synchrotron radiation in the electron beamline. Based upon an EGS4 Monte Carlo study and measurements at Frascati and KEK, Tromba and Rindi (TRO 90) have developed 
a semi-empirical expression for estimating dose rates from these bremsstrahlung photons. The total estimated dose rate at $10 \mathrm{~m}$ from the end of a straight section can be computed from:

$$
\dot{\mathrm{H}}[\mathrm{rem} / \mathrm{h}]_{10 \mathrm{~m}}=1.7 \times 10^{-14} \mathrm{E}^{2.43} \frac{\mathrm{P}}{760} \mathrm{IL} \text {, }
$$

where the electron energy $\mathrm{E}$ is in $\mathrm{MeV}$, the pressure $\mathrm{P}$ is in $\mathrm{mm}$, the circulating current $\mathrm{I}$ is in $\mathrm{e}^{-/} / \mathrm{s}$, and the length of the straight $L$ is in $m$. The above can be extended to other distances for $r>L$ and for points inside the radiation cone by using:

$$
\dot{\mathrm{H}}[\mathrm{rem} / \mathrm{h}]_{\mathrm{r}}=\dot{\mathrm{H}}_{10 \mathrm{~m}} \frac{(10+\mathrm{L} / 2)^{2}}{\mathrm{r}^{2}} \text {, }
$$

where $r(m)$ is the distance from the center of the straight section to the dose point.

Evaluation of the gas bremsstrahlung for the LEUTL was performed to estimate the dose rate from this component. The longest straight section in the LEUTL is $56 \mathrm{~m}$. The pressure was assumed to be $10^{-7} \mathrm{~mm}$, the electron current is $8.93 \times 10^{12} \mathrm{e}^{-/ \mathrm{s}}$, and the estimated dose rate at 10 $\mathrm{m}$ from the end of the straight is $8.5 \mathrm{mrem} / \mathrm{h}$. This amount of radiation is easily absorbed by the $\mathrm{Pb}$ stop at the end of the LEUTL tunnel.

\section{X Rays from rf Cavities}

The LEUTL system uses the if cavities and SLEDs that are provided for the linac. These were checked out during linac commissioning and any undesirable radiation from these units has been appropriately mitigated with added shielding.

\section{LEUTL System Accidental Losses}

A number of potential incidents in the LEUTL system and the dose rate consequences have been addressed already. For these incidents, the safety shutdown mechanisms are assumed to function properly and produce a shutdown in a brief period (generally, one or two pulses). The resulting doses are then either negligible or on the order of a few $\mu$ rems. In the maximum credible incident (MCI), the sequence of events is such that the incident continues for an unspecified amount of time. In this case, the total dose will be dependent on the duration of the incident. Previous calculations have expressed the MCI consequences as the dose rate, giving an implied dose for an incident of 1 hour duration. As stated in the APS Final SAD (APS 96), the APS dose not expect any loss scenario to last longer than 20 minutes. The discussion of the MCI for the LEUTL system and its dose rate consequences can be found in Appendix A. 


\subsection{Accidental Beam Spill}

The case of a 4-m-long spill along the LEUTL line, at the safety envelope power, has been discussed in sections 5.1.1 to 5.1.4. The dose rates ranged from $8 \mu \mathrm{rem} / \mathrm{h}$ to $13.1 \mathrm{rem} / \mathrm{h}$. Based upon a shutdown within two pulses, the total dose ranges from negligible to $0.15 \mathrm{mrem}$.

\subsection{Total Beam Loss at Beam Stops}

Sections 5.2.1 to 5.2.3 discuss the loss of the beam at various beam stops in the system. The dose rates ranged from $5 \mu \mathrm{rem} / \mathrm{h}$ to $105 \mathrm{mrem} / \mathrm{h}$. For a shutdown within two pulses, the total dose ranges from negligible to $1.3 \mu \mathrm{rem}$.

\subsection{Total Beam Loss at a Transition Piece}

In section 5.4, the case of a $20 \%$ beam loss on the transition piece of the undulator system was discussed. By scaling those results for a $100 \%$ loss, the dose rates become: $1.5 \mu \mathrm{rem} / \mathrm{h}$ on the south side of the tunnel, $2.5 \mu \mathrm{rem} / \mathrm{h}$ on the north side, and $990 \mathrm{mrem} / \mathrm{h}$ on the bermed roof. The total dose ranges from negligible for the side doses to $12 \mu \mathrm{rem}$ on the roof for a shutdown within two pulses.

\subsection{Total Beam Loss at Magnet SV2}

For this incident to occur, the magnet SV1 must be on while magnet SV2 fails (see Figure 3). Then the beam in the LEUTL line will be bent upward and sent through the synchrotron but will not be bent by SV2, and the beam will hit the magnet coils. This magnet is located under the bermed part of the synchrotron tunnel. For the dose rate directly above $(\sim \pi / 2$ radians), the dose point distance is $3.4 \mathrm{~m}$, and the shielding is $0.381 \mathrm{~m}$ of concrete and $1.676 \mathrm{~m}$ of compacted earth. The dose rate is $716 \mathrm{mrem} / \mathrm{h}$. For a shutdown after two pulses, the total dose is $8.4 \mu \mathrm{rem}$. Since the upward angle the beamline makes with the horizontal is 25 mradians, the slant penetration through the above-mentioned shields is greatly increased so that the dose rate in the $0^{0}$ direction is negligible. To protect potential occupants of the LEUTL tunnel, a 7.62-cm-thick W stop is placed in the beamline after the bending magnet. The nearest dose point in the LEUTL tunnel is about $10.5 \mathrm{~m}$ from the SV2 magnet. Radiation from the magnet must pass through the $30.48-\mathrm{cm}$ concrete wall of the synchrotron at an angle of about 0.185 radians and the $1.219 \mathrm{~m}$ concrete wall of the LEUTL (see Figure 1, region C). In addition, radiation coming down the LEUTL beampipe is attenuated by the W stop. The average dose rate $30 \mathrm{~cm}$ from the east concrete wall in the LEUTL is $131 \mathrm{mrem} / \mathrm{h}$. The total dose resulting from two pulses is $1.5 \mu \mathrm{rem}$.

\subsection{Total Beam Loss at Magnet SV1}

In this incident, the beam is being delivered to the LEUTL but the magnet SV1 fails (see D in Figure 3) so that the beam is not bent upwards but continues forward into a 15.24-cm $\mathrm{Pb}$ stop. This stop also has $15.24 \mathrm{~cm}$ of $\mathrm{Pb}$ on the Building 412 side. In Figure 3, the stop is in about the same location as the indicated beam stop and still within the region covered by the concrete blocks. The dose point in Building 412 is $3.86 \mathrm{~m}$ from the stop and is shielded by $15.24 \mathrm{~cm}$ of $\mathrm{Pb}$ and $1.96 \mathrm{~m}$ of concrete. On the mezzanine, the dose point is $3.433 \mathrm{~m}$ away and is shielded by $10.16 \mathrm{~cm}$ of Pb 
and $1 \mathrm{~m}$ of concrete. In the forward direction, the dose point in the LEUTL tunnel is about $46 \mathrm{~m}$ away and is shielded by $15.24 \mathrm{~cm}$ of $\mathrm{Pb}$ and $2.82 \mathrm{~m}$ of concrete. For operation at the safety envelope, the corresponding dose rates are $4.6 \mathrm{mrem} / \mathrm{h}, 503 \mathrm{mrem} / \mathrm{h}$, and $1 \mu \mathrm{rem} / \mathrm{h}$, respectively.

\section{Skyshine Dose Estimates}

There will be some skyshine radiation, produced during LEUTL operations, that penetrates both the side and roof of the shielding. Because the upward radiation goes through increased thickness as it slants through the side and roof of the shield, the simplifying assumption has been made that the effective thickness can be used in place of the actual thickness. Other assumptions are that half of the radiation goes up and half goes down (solid angle $=2 \pi$ ) and that the closest dose point at the nearest site boundary is $\sim 400 \mathrm{~m}$ away from the linac and PAR, $450 \mathrm{~m}$ away from the synchrotron, and $470 \mathrm{~m}$ away from the LEUTL tunnel. The power loss of $1 \times 10^{-4} / \mathrm{m}$ was used along the line to estimate the skyshine contribution for normal operation. All of this power is assumed to be lost to neutron production. Additional contributions are due to losses at the beam dumps and at the transition zone of the undulator system. In the LEUTL tunnel, the assumed losses on the transition piece $(100 \mathrm{~W})$ and in the particle beam dump $(400 \mathrm{~W})$ dominate the neutron production, whereas the loss along the beamline is $2.8 \mathrm{~W}$. In the synchrotron, the loss in the beam dump (50 W, assumed to be $1000 \mathrm{~W}$ for 0.05 operation time) also dominates the neutron production. The loss along the line is $2.3 \mathrm{~W}$. For all of these loss sites, all of the power is also assumed to go into neutron production. The loss rate for the PAR is taken as $15 \mathrm{~m} \times 1 \times 10^{-4} / \mathrm{m}=1.5 \times 10^{-3}(1000$ W) $(0.5)=0.75 \mathrm{~W}$. The factor 0.5 corrects for the total operating time of the LEUTL system taken as $50 \%$ of the APS operating time, except for the beam dump in the synchrotron. For the linac, the loss rate is $200\left(1 \times 10^{-4}\right) 1000(0.5)=10 \mathrm{~W}$.

\subsection{GRN Component}

The source term for the upward-directed GRN component (utilizing Equation (3)) is given by

$$
\mathrm{Q}_{\mathrm{GRN}}^{\prime}=1 / 2\left(1.21 \times 10^{8}(\mathrm{Z})^{0.66}\right)(\mathrm{n} / \mathrm{J}) \mathrm{W}(\mathrm{J} / \mathrm{s})=6.05 \times 10^{7} \mathrm{WZ}^{0.66} \mathrm{n} / \mathrm{s}
$$

into the upper hemisphere, where $\mathrm{W}$ is the power lost and the assumption is made that the component/stop is the major source of neutron production. For the particle beam dump, $Q_{G R N}^{\prime}$ is $4.44 \times$ $10^{11} \mathrm{n} / \mathrm{s}$; for the transition region, $Q_{G R N}^{\prime}$ is $1.04 \times 10^{11} \mathrm{n} / \mathrm{s}$; and for the loss along the line, $Q_{G R N}^{\prime}$ is $1.45 \times 10^{9} \mathrm{n} / \mathrm{s}$ for operation at the safety envelope. In the synchrotron, $\mathrm{Q}_{\mathrm{GRN}}^{\prime}$ is $5.54 \times 10^{10} \mathrm{n} / \mathrm{s}$ for the beam stop and $1.19 \times 10^{9}$ for the line contribution. The contributions from the PAR and linac are $3.9 \times 10^{8} \mathrm{n} / \mathrm{s}$ and $5.2 \times 10^{9} \mathrm{n} / \mathrm{s}$, respectively. The unattenuated neutrons that emerge through the roof and sides of the LEUTL tunnel are given by

$$
\begin{aligned}
Q_{G R N} & =Q_{G R N}^{\prime} e^{-11.35(23) / 161} \mathrm{e}^{-2.35(37.6) / 40} \mathrm{e}^{-1.9(142.2) / 33} \\
& =2.68 \times 10^{6} \mathrm{n} / \mathrm{s}, \text { for the particle beam dump, }
\end{aligned}
$$




$$
\begin{aligned}
\mathrm{Q}_{\mathrm{GRN}} & =\mathrm{Q}_{\mathrm{GRN}}^{\prime} \mathrm{e}^{-18(2.4) / 161} \mathrm{e}^{-1(7.87) / 100} \mathrm{e}^{-88.36 / 40} \mathrm{e}^{-270.18 / 33} \\
& =2.25 \times 10^{6} \mathrm{n} / \mathrm{s}, \text { for the transition region, and } \\
\mathrm{Q}_{\mathrm{GRN}} & =\mathrm{Q}_{\mathrm{GRN}}^{\prime} \mathrm{e}^{-0.25(7.87) / 100} \mathrm{e}^{-88.36 / 40} \mathrm{e}^{-270.18 / 33} \\
& =4.34 \times 10^{4} \mathrm{n} / \mathrm{s},
\end{aligned}
$$

giving a total emission of $4.97 \times 10^{6} \mathrm{n} / \mathrm{s}$, prorated for time of operation. The computation above assumes that the particle beam dump is shielded by effective thicknesses of $23 \mathrm{~cm}$ of $\mathrm{Pb}, 37.6 \mathrm{~cm}$ of concrete, and $1.422 \mathrm{~m}$ of earth in the upward direction. The transition piece is shielded by 2.4 $\mathrm{cm}$ of W, $1 \mathrm{~cm}$ of Fe, $37.6 \mathrm{~cm}$ of concrete, and $1.422 \mathrm{~m}$ of earth berm in the upward direction. The rest of the beamline is shielded (effectively) by $0.25 \mathrm{~cm}$ of Fe, $37.6 \mathrm{~cm}$ of concrete, and $1.422 \mathrm{~m}$ of earth in the upward direction.

The skyshine dose equivalent rate at $470 \mathrm{~m}$ away can be estimated from the modified expression (Equation 8.6.3 of MOE 91):

$$
\dot{\mathrm{H}}_{\mathrm{GRN}}=\frac{\mathrm{aQ}_{\mathrm{GRN}} \exp -\frac{\mathrm{r}}{\lambda}}{7(4) \pi \mathrm{r}^{2}},
$$

where $a$ and $\lambda$ are constants, $Q$ is the source strength $(n / s)$, and $r$ is the distance to the dose point in $\mathrm{cm}$. Values of the constants a and $\lambda$ quoted from measurements at DESY by Rindi and Thomas (RIN 75) were used in the estimate. The values chosen $\left(a=7\right.$ and $\lambda=3.3 \times 10^{4} \mathrm{~cm}$ ) give the largest fluence rate (most conservative) values for the DESY measurements. On the basis of $4000 \mathrm{~h}$ of exposure, the total annual GRN dose would be $0.17 \mathrm{mrem}$ at the nearest site boundary, approximately $470 \mathrm{~m}$ away from the LEUTL tunnel. To this must be added the contributions from the synchrotron, PAR, and linac. Using the same methodology as above, the total annual GRN dose contributions from the synchrotron, PAR, and linac are $1.87 \mathrm{mrem}, 27 \mu \mathrm{rem}$, and $11 \mu \mathrm{rem}$, respectively. This indicates a total annual dose from the GRN component of $2.08 \mathrm{mrem}$.

\subsection{MEN Component}

For $700-\mathrm{MeV}$ electrons, the dose factors for the MEN component at $90^{\circ}$ adapted from (CER 84), are $2.65 \times 10^{-2} \mathrm{mrem} / \mathrm{J}$ at $1 \mathrm{~m}$ for steel or copper and $1.59 \times 10^{-2} \mathrm{mrem} / \mathrm{J}$ at $1 \mathrm{~m}$ for $\mathrm{Pb}$ or W. Using an average value of $4.4 \times 10^{-8} \mathrm{rem} / \mathrm{n} / \mathrm{cm}^{2}$ for neutrons between $25-100 \mathrm{MeV}$, obtained from ICRP 51 (ICP 87), results in an estimated MEN neutron yield of $9.82 \times 10^{7} \mathrm{n} / \mathrm{J}$ in $\mathrm{Fe}$ and $\mathrm{Cu}$ and $5.89 \times 10^{7} \mathrm{n} / \mathrm{J}$ in $\mathrm{Pb}$ or W. The source terms ( $\mathrm{Q}_{\text {MEN }}$ ) for the upward-directed MEN component are given by the neutron yield multiplied by $1 / 2$ the power lost- $1.18 \times 10^{10} \mathrm{n} / \mathrm{s}$ for the LEUTL particle beam dump, $2.95 \times 10^{9} \mathrm{n} / \mathrm{s}$ for the transition piece, and $1.37 \times 10^{8} \mathrm{n} / \mathrm{s}$ for the beamlinefor neutrons directed into the upper atmosphere for operation at the safety envelope. Correspond- 
ing values of upward-directed MEN neutrons for the synchrotron, PAR, and linac are $2.00 \times 10^{7}$ $\mathrm{n} / \mathrm{s}, 5.76 \times 10^{5} \mathrm{n} / \mathrm{s}$, and $8.78 \times 10^{5} \mathrm{n} / \mathrm{s}$, respectively. The unattenuated neutrons that emerge through the LEUTL roof are $\mathrm{Q}_{\mathrm{MEN}}=5.1 \times 10^{6} \mathrm{n} / \mathrm{s}$. The skyshine dose equivalent rate at $470 \mathrm{~m}$ away can be estimated from Equation (15) with $Q_{\mathrm{MEN}}$ replacing $\mathrm{Q}_{\mathrm{GRN}}$ :

$$
\dot{\mathrm{H}}_{\mathrm{MEN}}=4.42 \times 10^{-5} \mathrm{mrem} / \mathrm{h} \text {. }
$$

On the basis of $4000 \mathrm{~h}$ of exposure, the total annual MEN dose would be 0.18 mrem at the nearest site boundary. The annual contributions from the synchrotron, PAR, and linac are $0.80 \mathrm{mrem}, 34$ $\mu \mathrm{rem}$, and $52 \mu \mathrm{rem}$, respectively. The total annual dose for the MEN component is $1.066 \mathrm{mrem}$.

\subsection{HEN Component}

For $700-\mathrm{MeV}$ electrons, the dose factors for the HEN component at $90^{\circ}$, adapted from (CER 84), are $2.48 \times 10^{-3} \mathrm{mrem} / \mathrm{J}$ at $1 \mathrm{~m}$ for $\mathrm{Fe}$ and $\mathrm{Cu}$ and $1.49 \times 10^{-3} \mathrm{mrem} / \mathrm{J}$ at $1 \mathrm{~m}$ for $\mathrm{Pb}$ and $\mathrm{W}$. Using an average value of $1.0 \times 10^{-7} \mathrm{rem} / \mathrm{n} / \mathrm{cm}^{2}$ for neutrons between $100-7700 \mathrm{MeV}$, adapted from ICRP 51 (ICP 87), results in an estimated HEN neutron yield of $6.47 \times 10^{6} \mathrm{n} / \mathrm{J}$ in $\mathrm{Fe}$ and $\mathrm{Cu}$ and $3.88 \times 10^{6} \mathrm{n} / \mathrm{J}$ in Al. The source terms ( $\mathrm{Q}_{\mathrm{HEN}}^{\prime}$ ) for the upward-directed HEN component are given by the neutron yield multiplied by $1 / 2$ the power lost-7.78 $\times 10^{8} \mathrm{n} / \mathrm{s}$ for the particle beam dump, $1.94 \times 10^{8}$ for the transition piece, and $9.07 \times 10^{6} \mathrm{n} / \mathrm{s}$ the beamline-for neutrons directed into the upper atmosphere at safety envelope operation. The unattenuated neutrons that emerge through the roof are $\mathrm{Q}_{\mathrm{HEN}}=4.33 \times 10^{6} \mathrm{n} / \mathrm{s}$. The skyshine dose equivalent rate at $470 \mathrm{~m}$ away can be estimated from Equation (15) with $Q_{\mathrm{HEN}}$ replacing $Q_{\mathrm{GRN}}$ :

$$
\dot{\mathrm{H}}_{\mathrm{HEN}}=3.75 \times 10^{-5} \mathrm{mrem} / \mathrm{h} \text {. }
$$

On the basis of $4000 \mathrm{~h}$ of exposure, the total HEN dose would be $0.15 \mathrm{mrem}$ at the site boundary. The unattenuated HEN that emerge from the synchrotron, PAR, and linac are $2.73 \times 10^{6} \mathrm{n} / \mathrm{s}, 2.32$ $\times 10^{5} \mathrm{n} / \mathrm{s}$, and $9.07 \times 10^{5} \mathrm{n} / \mathrm{s}$, respectively. These components contribute $0.11 \mathrm{mrem}, 14 \mu \mathrm{rem}$, and $54 \mu \mathrm{rem}$, respectively, to the annual HEN dose, resulting in a total of $0.33 \mathrm{mrem}$ from the HEN component.

The estimated total annual dose equivalent from neutron skyshine is computed to be $3.48 \mathrm{mrem}$ at the nearest site boundary. Previous estimates of the contribution to the skyshine dose of skyward-directed, scattered bremsstrahlung radiation from the linac test stand (LTS), indicated this component to be negligible. Since the roof on the LEUTL system is more than $1 \mathrm{~m}$ thick, the attenuation of radiation by the LEUTL should be comparable to the LTS and the scattered bremsstrahlung from the LEUTL should also be negligible. 


\section{Direct Radiation at the Site Boundary}

Because the LEUTL is located in the infield of the APS, it is entirely surrounded by the APS storage ring. Any direct radiation from the components of the LEUTL must travel 400 to $470 \mathrm{~m}$ to the nearest dose point, in addition to the $160 \mathrm{~cm}$ of concrete-equivalent shielding on the storage ring tunnel. The attenuation factor for the concrete is about 2000 , so all direct radiation contributions from components in the infield are essentially negligible ( $<1 \mu \mathrm{rem})$.

\section{Radioactive and Noxious Gas Emissions}

Sources of radioactive and noxious gases found in the air of the LEUTL tunnel system result from loss of particles in the components of the system and escape of bremsstrahlung radiation from the components or from beam stops. As previously discussed, electron absorption results in bremsstrahlung formation and the interaction of this component with air results in the production of a number of radioactive products, primarily through the photonuclear reaction $(\gamma, \mathrm{n})$ (CER 84). Of the many possible radionuclides formed, only three (C-11, N-13, and O-15) are of importance in the operation of the APS. Of these three radionuclides, $\mathrm{N}-13$ makes up about $90 \%$ of the concentration found in air (SWA 79a). One other potential radionuclide, Ar-41, is formed by thermal neutron capture in argon. Since this is a second-order reaction (requiring slowing down of the fast neutrons created by the bremsstrahlung and capture by argon, which is $<1 \%$ abundant in air), the production of this component will be negligible. Irradiation of air by photon radiation below the threshold for neutron production (6-20 MeV in most materials) results in the production of ozone and oxides of nitrogen (SWA 79a). The products ozone $\left(\mathrm{O}_{3}\right)$, nitrogen dioxide $\left(\mathrm{NO}_{2}\right)$, and nitric acid $\left(\mathrm{HNO}_{3}\right)$ are the most prominent components formed.

\subsection{Radioactive Gas Formation}

The mechanism for formation of radionuclides in air is the photoneutron interaction of bremsstrahlung with air nuclei (SWA 79a). The $(\gamma, \mathrm{n})$ threshold for air is $10.55 \mathrm{MeV}$ for the formation of $\mathrm{N}-13$, and $15.67 \mathrm{MeV}$ for $\mathrm{O}-15$. In addition, some $\mathrm{C}-11$ is formed by photon spallation of both nitrogen and oxygen. Using the neutron yield expression given by Equation (3) and the effective $\mathrm{Z}$ of 7.26, according to Schaeffer ( $\mathrm{SCH} 73$ ), the neutron yield $\mathrm{Y}$ in air is

$$
\mathrm{Y}=1.21 \times 10^{8} \mathrm{Z}^{0.66}(\mathrm{n} / \mathrm{J})=4.5 \times 10^{8}(\mathrm{n} / \mathrm{J}) .
$$

Implicit in the release of the neutron is the formation of an unstable nucleus, which may be radioactive. We assume the yield of neutrons is also the yield of radionuclides. The yield of MEN and HEN neutrons increases the total neutron yield by about $15 \%$, but ignoring their contribution should not make a significant difference in the yield of radionuclides.

The change in the number of radioactive atoms present per unit time, $\mathrm{dN} / \mathrm{dt}$, is

$$
\mathrm{dN} / \mathrm{dt}=\mathrm{WfY}\left(1-\mathrm{e}^{-\mathrm{x} / \lambda}\right)-\left(\lambda_{\mathrm{R}}+\mathrm{k} \mathrm{FR} / \mathrm{V}\right) \mathrm{N} \text { atoms } / \mathrm{s},
$$


where W (watts) is the particle beam power loss; $f$ is the fraction of particle energy that converts to bremsstrahlung and escapes into air; $\mathrm{x}$ is the average air path in $\mathrm{m}$, estimated to be $3.5 \mathrm{~m}$ for the LEUTL tunnel; $\lambda$ is the attenuation length in air for bremsstrahlung in $\mathrm{m}$ ( $385 \mathrm{~m}$ as suggested in CER 84); $\lambda_{R}$ is the radioactive decay constant of the radionuclide that is formed, $\mathrm{s}^{-1} ; \mathrm{k}$ is a factor to account for imperfect mixing of the radionuclide in air (assumed to be $1 / 10$ ); $\mathrm{V}$ is the volume of the region being ventilated $\left(\mathrm{m}^{3}\right)$; and $\mathrm{FR}$ is the ventilation flow rate $\left(\mathrm{m}^{3} / \mathrm{s}\right)$. For initial conditions $\mathrm{N}=0$ for $\mathrm{t}=0$, the solution is

$$
N=\frac{W f y\left(1-e^{-x / \lambda}\right)\left(1-e^{-\left(\lambda_{R}+k F R / V\right) t}\right)}{\lambda_{R}+k F R / V}
$$

and the activity is $A=\lambda_{R} N$, so that

$$
\mathrm{A}=\frac{\lambda_{\mathrm{R}} \mathrm{WfY}\left(1-\mathrm{e}^{-\mathrm{x} / \lambda}\right)\left(1-\mathrm{e}^{-\left(\lambda_{\mathrm{R}}+\mathrm{kFR} / \mathrm{V}\right) \mathrm{t}}\right)}{\lambda_{\mathrm{R}}+\mathrm{kFR} / \mathrm{V}}(\mathrm{dis} / \mathrm{s})
$$

Since the radionuclides that are formed all have short half lives ( $<20.5 \mathrm{~min}$.), saturation is achieved quickly so that the activity at saturation becomes

$$
A=\frac{\lambda_{R} W f Y\left(1-e^{-x / \lambda}\right)}{\lambda_{R}+k F R / V} \text { (dis/s), }
$$

where the decay constant $\lambda_{R}\left(\mathrm{~s}^{-1}\right)$ is for $\mathrm{N}-13$ (half life $\sim 10 \mathrm{~min}$ ), which is the most abundant radionuclide formed. The equilibrium concentration is then obtained from

$$
C=\frac{A}{3.7 \times 10^{4}(\mathrm{dis} / \mathrm{s} \mu \mathrm{Ci}) \mathrm{V}(\mathrm{cc})}(\mu \mathrm{Ci} / \mathrm{cc})
$$

where $\mathrm{V}$ is the volume of the LEUTL component being evacuated. Combining Equations (19) and (20), the concentration is given by

$$
C=\frac{\lambda_{R} W f Y\left(1-e^{-x / \lambda}\right)}{3.7 \times 10^{4} V\left(\lambda_{R}+k F R / V\right)}
$$

$\mathrm{kFR} / \mathrm{V}$ is $4.23 \times 10^{-5} \mathrm{~s}^{-1}$ for the LEUTL tunnel. FR is $450 \mathrm{cfm}$ and $\mathrm{V}$ is $5.02 \times 10^{8} \mathrm{~cm}^{3}$. Details of the methodology used to estimate $f$ for the different components are given in Appendix B of MOE 94. Of the components that may contribute to radiogas formation-particle beam dump, the transition piece, and the LEUTL beamline-the fraction of energy escaping ( $f$ ), modified for the fraction of operating time, is negligible for the particle beam dump; $6.5 \times 10^{-3}$ for the transition piece, 
and $5 \times 10^{-2}$ for the beamline losses. Using appropriate values for $\mathrm{W}$ and $\mathrm{f}$ for each of the contributing components, the total equilibrium concentration in the tunnel is

$$
\mathrm{C}=3.4 \times 10^{-7} \mu \mathrm{Ci} / \mathrm{cc} \text {. }
$$

This concentration is a factor of about 12 lower than the DAC (Derived Air Concentration) for occupational exposure: $4 \times 10^{-6} \mu \mathrm{Ci} / \mathrm{cc}$ in 10CFR835 (CFR 94). Once the operation is shut down, this concentration will rapidly decrease due to both radioactive decay and the ventilation rate. Similar computations for the synchrotron, PAR, and linac yielded equilibrium concentrations of $1.65 \times 10^{-8} \mu \mathrm{Ci} / \mathrm{cc}, 5.67 \times 10^{-9} \mu \mathrm{Ci} / \mathrm{cc}$, and $5.72 \times 10^{-8} \mu \mathrm{Ci} / \mathrm{cc}$, respectively. These are all well below the DAC.

\subsection{Noxious Gas Formation}

The basis of the formation of ozone $\left(\mathrm{O}_{3}\right)$ and other noxious gases (nitrogen oxides) in air is photon irradiation of the air molecules (CER 84), causing dissociation of oxygen molecules and leading to an active free atom of oxygen attaching to an oxygen molecule. Ozone also reacts with other materials formed in air, such as nitrogen oxide, to form nitrogen dioxide $\left(\mathrm{NO}_{2}\right)$, that reacts with water vapor in air to form nitric acid $\left(\mathrm{HNO}_{3}\right)$. The radiolytic yield of these products is expressed by the quantity, $\mathrm{G}$, which is the number of molecules formed per unit energy absorbed. These values are usually given as molecules per $100 \mathrm{eV}$ absorbed. Because of its low Threshold Limit Value (TLV) of 0.05 parts per million (ppm) for occupational exposure conditions $(8 \mathrm{~h}$ per day, $40 \mathrm{~h}$ per week) for heavy work conditions (ACG 96), ozone is the most important noxious product. Ozone is also chemically active and decomposes spontaneously with a chemical half life of about $50 \mathrm{~min}$.

The TLV values for $\mathrm{NO}_{2}$ and $\mathrm{HNO}_{3}$ are much higher at 3 and $2 \mathrm{ppm}$, respectively, than that for ozone. Estimates of the production of $\mathrm{O}_{3}, \mathrm{NO}_{2}$, and $\mathrm{HNO}_{3}$ are based upon $\mathrm{G}$ values of $10,4.8$, and 1.5, respectively (SWA 79a, CER 84). Adapting the expression from Goebel (CER 81), the change in the number of ozone atoms present per $\mathrm{s}, \mathrm{dN} / \mathrm{dt}$, is

$$
\mathrm{dN} / \mathrm{dt}=\mathrm{PG}-\alpha \mathrm{N}-(\mathrm{KP} / \mathrm{V}) \mathrm{N}-(\mathrm{FR} / \mathrm{kV}) \mathrm{N},
$$

where

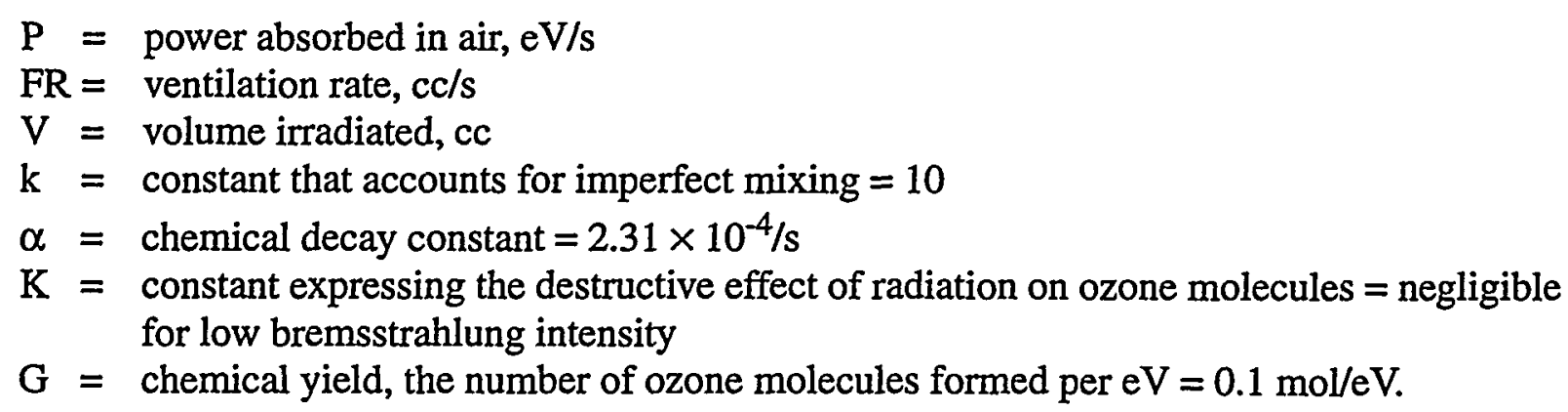


The solution for initial conditions $\mathrm{N}=0$ when $\mathrm{t}=0$ is

$$
N=\frac{P G}{(\alpha+K P / V+F R / 10 V)}\left(1-e^{-(\alpha+K P / V+F R / 10 V) t}\right)
$$

Since the TLV is given in ppm, it is desirable to express the number of ozone molecules in terms of that unit, and

$$
\mathrm{C}_{\mathrm{O}_{3}}=\frac{\mathrm{N} \text { (mol ozone })}{\mathrm{V}(\mathrm{cc} \text { of air }) 2.463 \times 10^{13}(\mathrm{~mol} \text { ozone/(cc of air }) \mathrm{ppm}} .
$$

The power absorbed, $\mathrm{P}$, for the case of bremsstrahlung resulting from loss of particles may be expressed as

$$
\mathrm{P}=(\mathrm{Wf} / \lambda)\left(6.25 \times 10^{18} \mathrm{eV} / \mathrm{J}\right)(\mathrm{eV} / \mathrm{s}),
$$

where $W$ (watts) is the particle beam power loss, $f$ is the fraction of particle energy that converts to bremsstrahlung and escapes into air (details of the methodology for the estimation of $f$ are given in Appendix B of MOE 94), $\mathrm{x}$ is the average air path in $\mathrm{m}$ ( $3.5 \mathrm{~m}$ for the LEUTL tunnel), and $\lambda$ is the attenuation length in air for bremsstrahlung in $\mathrm{m}$ (385 $\mathrm{m}$ ). Combining Equations (23), (24), and (25), and noting that the term involving $K$ is negligible for the low intensity of bremsstrahlung from the components, one arrives at the equilibrium concentration of ozone in the LEUTL tunnel:

$$
\mathrm{C}_{\mathrm{O}_{3}}=\frac{2.54 \times 10^{5} \mathrm{~W}(\mathrm{f} \times \mathrm{G})}{\lambda \mathrm{V}(0.000231+0.0000423)} \mathrm{ppm}
$$

Substituting values for the parameters in Equation (26) gives

$$
\mathrm{C}_{\mathrm{o}_{3}}=1.68 \times 10^{-3} \sum_{\mathrm{i}=1}^{3} \mathrm{~W}_{\mathrm{i}} \mathrm{f}_{\mathrm{i}} \mathrm{ppm}
$$

contributed by bremsstrahlung. The composite concentration is $2.7 \times 10^{-3} \mathrm{ppm}$, which is well below the TLV of $0.05 \mathrm{ppm}$. The total estimated annual release of noxious products due to bremsstrahlung would be $32 \mathrm{~g}$ of $\mathrm{O}_{3}, 15 \mathrm{~g}$ of $\mathrm{NO}_{2}$, and $5 \mathrm{~g}$ of $\mathrm{HNO}_{3}$ for the LEUTL tunnel based upon scaling the ozone production by the ratio of $\mathrm{G}$ values for the other components. The total annual contributions due to bremsstrahlung from the synchrotron, $P A R$, and linac are $97 \mathrm{~g}$ of $\mathrm{O}_{3}$, $47 \mathrm{~g}$ of $\mathrm{NO}_{2}$, and $15 \mathrm{~g}$ of $\mathrm{HNO}_{3}$, respectively. The equilibrium concentrations of ozone in these components ranged from 280-2800 times lower than the TLV. 
With respect to noxious gas formed by escaping synchrotron radiation, an estimate of the contribution was made by Moe (MOE 91) for the storage ring. Adapting Equation 10.3.4.6 from that report to the case of the equilibrium concentration of ozone in the LEUTL tunnel gives

$$
\mathrm{C}_{\mathrm{O}_{3}}=\frac{4.06 \times 10^{-15} \mathrm{P}}{\mathrm{V}(\alpha+\mathrm{FR} / 10 \mathrm{~V})}
$$

where $P$ was based upon a circulating current of $100 \mathrm{~mA}$ and a different value of $F R / k V$ was used at that time. The quantity $\mathrm{P}$ is the total absorbed power rate in air from the escaping synchrotron radiation. The analysis in section 7 showed that no synchrotron radiation is expected to penetrate through the stainless steel vacuum tube so the contribution from this source would be negligible. So, the estimated total annual releases of $\mathrm{O}_{3}, \mathrm{NO}_{2}$, and $\mathrm{HNO}_{3}$ are as given above for the bremsstrahlung component.

\section{Activation of Beam Stop Materials and LEUTL Components}

As discussed earlier, the photoneutron interaction of bremsstrahlung with the nuclei of materials leads to the formation of radioactive products in the air. This same interaction produces the major portion of activated components in the LEUTL materials. The particular radionuclides that are produced will depend upon the $(\gamma, n),(\gamma, 2 n)$, and photospallation cross sections for the various materials that are present in these components. The radioactive materials that are formed have a range of half lives from seconds to more than $10^{5}$ years (SWA 79a). The intensity of these radioactive products at some time following a shutdown is a function of the composition and amount of a given material present, the reaction cross section, and the radioactive product half life. The materials of interest for the LEUTL operation are aluminum, iron (in steel), copper, lead, and tungsten. $\mathrm{Pb}$ is used as shielding for the beam stops in the synchrotron and LEUTL tunnels and at other locations along the line. The $\mathrm{e}^{+}$beam vacuum chamber is stainless steel, tungsten is in the ID transition piece, and iron is in the magnets. Radioactivity builds up during system operation, and at shutdown there is initial rapid decay of the shorter-lived materials, then a slower decay of intermediate half life materials, leaving only the residual longer-lived components. At the time of decommissioning, only the longer-lived components remain. For daily operation of the facility, the short-lived material is important because this activity in the LEUTL system components may be the source of an elevated radiation field that may limit access time to the area.

\subsection{Residual Radioactivity Estimates}

An estimate of the activity of a radionuclide formed by $(\gamma, \mathrm{n})$ reactions in a particular material can be obtained from Equation (3), modified to account for the abundance of the particular target isotope of a given element that becomes activated. We again assume that the yield of neutrons is also the yield of radionuclide atoms. This may be expressed as

$$
\mathrm{Y}^{\prime}=\mathrm{FY}=1.21 \times 10^{8} \mathrm{FZ}^{0.66}(\text { atoms } / \mathrm{sW}) \text {, }
$$


where $\mathrm{F}$ is the fractional abundance of the isotope and $\mathrm{Z}$ is the atomic number of the element. For example, copper activation $(\mathrm{Z}=29)$ is the result of activation of $\mathrm{Cu}-63(\mathrm{~F}=0.691)$ and $\mathrm{Cu}-65(\mathrm{~F}$ $=0.309$ ), leading to a number of radionuclides: Co-58, Co-58m, Co- $60, \mathrm{Ni}-63, \mathrm{Cu}-61, \mathrm{Cu}-62$, and $\mathrm{Cu}-64$ (SWA 79a). Most of these radionuclides have half lives of minutes to hours so they decay away quickly and do not contribute to residual radioactivity. But these radionuclides are important for short-term irradiations.

The change in the number of radioactive atoms present per unit time, $\mathrm{dN} / \mathrm{dt}$, is given by

$$
\mathrm{dN} / \mathrm{dt}=\mathrm{WfY} \mathrm{Y}^{\prime}-\lambda_{\mathrm{R}} \mathrm{N} \quad(\text { atoms } / \mathrm{s}),
$$

where $W$ (watts) is the particle beam loss, $f$ is the fraction of particle energy converted to bremsstrahlung and absorbed in the activated material (taken as 0.5 if no calculated value is available), and $\lambda_{R}$ is the radioactive decay constant of the radionuclide produced, $\mathrm{s}^{-1}$. For the initial conditions, $\mathrm{N}=0$ for $\mathrm{t}=0$, the solution is

$$
\mathrm{N}=\frac{\mathrm{WfY^{ \prime }}}{\lambda_{\mathrm{R}}}\left(1-\mathrm{e}^{-\lambda_{\mathrm{R}} \mathrm{t}}\right) \text { (atoms), }
$$

and since the activity $A=\lambda_{R} N$, the activity in units of millicuries ( $m$ Ci) becomes

$$
\mathrm{A}=W f Y^{\prime}\left(1-\mathrm{e}^{-\lambda_{\mathrm{R}} \mathrm{t}}\right)(\mathrm{dis} / \mathrm{s})=\frac{W f Y^{\prime}}{3.7 \times 10^{7}}\left(1-\mathrm{e}^{-\lambda_{\mathrm{R}} \mathrm{t}}\right)(\mathrm{mCi}) .
$$

The product WfY' is the production rate of radionuclides of a given half life for $(\gamma, \mathrm{n})$ reactions. Similar expressions may be developed for the production rates of radionuclides of a certain half life for $(\gamma, 2 \mathrm{n})$ and photospallation reactions, given the yield values.

The realization of saturation activity for all radioactive products is more complicated than in the case of air activation, which contains only short half-life positron emitters (half lives $\leq 21 \mathrm{~min}$ ). One may assume that saturation is approximately reached when the operation time is about 3 times the half life of the radionuclide being formed. The saturation activity, $A_{S}$, is then

$$
A_{s}=\frac{W f Y^{\prime}}{3.7 \times 10^{7}}(\mathrm{mCi})
$$

For each of the potential activated materials, Swanson (SWA 79a) has prepared tables listing the saturation activities of the $(\gamma, n),(\gamma, 2 n)$, and photospallation products. These are in Tables $\mathrm{XXIb}-\mathrm{XXVIlb}$, which contain information about the saturation activity $(\mathrm{Ci} / \mathrm{kW})$ of a given radionuclide and the exposure rate at 1 meter from the material of saturation activity, uncorrected for self-absorption. 
The data in the these tables has been used to estimate the expected radiation fields following certain operation times, the residual field at later times, and the importance of the residual radiation field for continued daily operation. The results are discussed in this section. Results for some other materials are discussed by Moe (MOE 93a-93c, 94).

\subsubsection{Aluminum}

The synchrotron beam stop is made of aluminum, lead, and polyethylene. Irradiation of the aluminum can produce these activities: $\mathrm{C}-11, \mathrm{~N}-13, \mathrm{O}-15, \mathrm{Ne}-24, \mathrm{Al}-25, \mathrm{AL}-26 \mathrm{~m}$ with half lives between $6.37 \mathrm{~s}$ and $20.5 \mathrm{~min}$, and F-18 with a half life of $110 \mathrm{~min}$. For estimating aluminum activation during LEUTL operations, it is assumed that $1000 \mathrm{~W}$ is the power lost locally in the beam stop, $100 \%$ in the aluminum. Although the loss will be distributed throughout the aluminum, the assumption is made that a point loss occurs in order to get a conservative estimate of the maximum possible radiation dose rate. Operation for $1 \mathrm{~h}$ results in approximate saturation for all radionuclides except $\mathrm{F}-18$. The estimated combined exposure rate at $1 \mathrm{~m}$ is $2.7 \mathrm{R} / \mathrm{hkW}$, which gives $2.7 \mathrm{R} / \mathrm{h}$ at $1 \mathrm{~m}(28.9 \mathrm{R} / \mathrm{h}$ at $1 \mathrm{ft})$, immediately after shutdown. The major contribution is from Al-26m $\left(T_{1 / 2}=6.37 \mathrm{~s}\right)$ so that, after a minute or so, the residual reading should be $<120 \mathrm{mR} / \mathrm{h}$ at $1 \mathrm{~m}$. Operation for $8 \mathrm{~h}$ will cause this residual radiation field to slightly build up due to F-18. So the residual radiation field in this material is not important (only small activities of F-18 with a half life of $110 \mathrm{~min}$ are produced during prolonged operation).

Using information from Swanson (SWA 79a) on the saturation activity of aluminum activation products, the long-term residual activities of Na-22 and Al-26 in the LEUTL system are estimated to be about $110 \mathrm{mCi}$ and $112 \mu \mathrm{Ci}$, respectively.

\subsubsection{Copper}

As mentioned in section 14.1, activated copper consists of several radionuclides that include half lives from about $10 \mathrm{~min}$ to nearly 100 years. Relevant activities that may contribute to the residual radioactivity in the system are Co-60 (half life $=5.27 \mathrm{y}$ ) and Ni-63 (half life $=92 \mathrm{y}$ ). Estimates of the activities of these radionuclides at time of shutdown of the APS are contained in APS-LS-141 Revised. These estimates assume operation of the storage ring over many years at $7 \mathrm{GeV}$ and 300 $\mathrm{mA}$ of circulating current in order that a build-up of activity will occur. For short operation time and lower power, only a negligible amount of activity will be formed.

For the purpose of estimating copper activation during LEUTL operations, it is assumed that $100 \%$ of the power is lost locally in the material. The assumption is made that a point loss occurs in order to get a conservative estimate of the radiation field. Operation for $1 \mathrm{~h}$ with a copper absorber results in about $97 \%$ of the radiation field being produced by $\mathrm{Cu}-62$ (half life $9.76 \mathrm{~min}$ ). Other products include $\mathrm{Co}-58 \mathrm{~m}, \mathrm{Cu}-61$, and $\mathrm{Cu}-64$. The estimated exposure rate immediately after shutdown for a $1 \mathrm{~h}$ run is $4.56 \mathrm{R} / \mathrm{h}$ at $1 \mathrm{~m}$ for $1 \mathrm{~kW}$ operation. After $1.5 \mathrm{~h}$, the field is about $100 \mathrm{mR} / \mathrm{h}$ at $1 \mathrm{~m}$, only $7 \%$ from Cu-62. For an 8-h run, the estimated field would be $5.12 \mathrm{R} / \mathrm{h}$ at 1 $\mathrm{m}$; down to $120 \mathrm{mR} / \mathrm{h}$ after $1.5 \mathrm{~h}$ decay. The radiation field is then mainly from Cu-61 (half life = $3.32 \mathrm{~h}$ ) and $\mathrm{Cu}-64$ (half life $=12.8 \mathrm{~h}$ ). For an 8 -h run followed by a 16 -h cool down, the estimated radiation field would be about $120 \mathrm{mR} / \mathrm{h}$ at $1 \mathrm{~m}$ from Cu-64 activity alone. Daily operation at the safety envelope for $8 \mathrm{~h}$ will cause this residual radiation field to build up slightly. The residual 
radiation field is important for copper, since time for maintenance of the equipment very near the activated copper may need to be limited.

Using information from Swanson (SWA 79a) on the saturation activity of copper activation products, the long-term residual activity of Co-60 in the LEUTL system is estimated to be about 10 $\mathrm{mCi}$.

\subsubsection{Iron}

Continuous operation for $1 \mathrm{~h}$ with an iron absorber results in about $90 \%$ of the saturation exposure rate. The main activities are $\mathrm{Mn}-52 \mathrm{~m}, \mathrm{Mn}-56, \mathrm{Fe}-52$, and Fe-53. The estimated combined exposure rate, based upon a loss rate of $1 \times 10^{-4} / \mathrm{m}$ of beamline $(0.1 \mathrm{~W} / \mathrm{m}$ and assuming a point loss), at $1 \mathrm{~m}$ is about $30 \mathrm{mR} / \mathrm{h}$, contributed mainly by $\mathrm{Mn}-52 \mathrm{~m}$ (half life $=21.1 \mathrm{~min}$ ) and Fe-53 (half life $=8.51 \mathrm{~min}$ ). After about $1.5 \mathrm{~h}$, the exposure rate should be about $23 \mu \mathrm{R} / \mathrm{h}$ at $1 \mathrm{~m}$. For $8 \mathrm{~h}$ operation, Mn-56 (half life $=2.576 \mathrm{~h}$ ) and Fe-52 (half life $=8.2 \mathrm{~h}$ ) will build up enough to make a slight contribution initially, $\sim 170 \mu \mathrm{R} / \mathrm{h}$ at $1 \mathrm{~m}$ after $1.5 \mathrm{~h}$, and about the same after $16 \mathrm{~h}$ cooldown. The residual radiation field is only slightly important in the case of steel in the beamline and magnets.

Using information from Swanson (SWA 79a) on the saturation activity of iron activation products, the long-term residual activities of Mn-54 and Sc-46 in the LEUTL system are estimated to be about $9 \mathrm{mCi}$ and $3 \mathrm{mCi}$, respectively.

\subsubsection{Lead}

Using lead (provided it is free of antimony) as a stop material will result in the activation of these products: $\mathrm{Tl}-206, \mathrm{Tl}-207 \mathrm{~m}, \mathrm{Tl}-207, \mathrm{~Pb}-202 \mathrm{~m}, \mathrm{~Pb}-203 \mathrm{~m}$, and $\mathrm{Pb}-204 \mathrm{~m}$. The estimated exposure rate at $1 \mathrm{~m}$ is $0.636 \mathrm{R} / \mathrm{hkW}$ (not corrected for self-shielding) immediately after $1 \mathrm{~h}$ of operation at the safety limit of the LEUTL. The radiation field after $1.5 \mathrm{~h}$ would still be about $60 \mathrm{mR} / \mathrm{h}$ at $1 \mathrm{~m}$ but would be negligible by the next day. For $8 \mathrm{~h}$ operation, the estimated initial radiation field would increase to $815 \mathrm{mR} / \mathrm{h}$ at $1 \mathrm{~m}$, down to $77 \mathrm{mR} / \mathrm{h}$ after $1.5 \mathrm{~h}$ decay, and negligible the next day. $\mathrm{Pb}-204 \mathrm{~m}$ (half life $=67 \mathrm{~min}$ ) accounts for most of the radiation field after a few minutes. The residual radioactivity is only slightly important for this material.

Using information from Swanson (SWA 79a) on the saturation activity of lead activation products, the long-term residual activity of Tl-204 in the LEUTL system is estimated to be about 20 $\mathrm{mCi}$.

\subsubsection{Tungsten}

The transition piece material is essentially tungsten $(\mathrm{Z}=74)$, which has four isotopes that can be activated: $\mathrm{W}-182(\mathrm{~F}=0.264), \mathrm{W}-183(\mathrm{~F}=0.144), \mathrm{W}-184(\mathrm{~F}=0.306)$ and $\mathrm{W}-186(\mathrm{~F}=0.284)$. Only W-182 and W-183 contribute relatively long-lived radionuclides (W-181 of half life $=140 \mathrm{~d}$ and Ta-182 of half life $115.1 \mathrm{~d}$ ) that would constitute residual radioactivity after prolonged operation. The transition piece is assumed to intercept $20 \%$ of the LEUTL beam during normal operations, for calculational purposes. For a tungsten stop, $1 \mathrm{~h}$ operation would produce the activities: 
Ta-180m, Ta-182m, Ta- $184, \mathrm{Ta}-185, \mathrm{~W}-183 \mathrm{~m}$, and $\mathrm{W}-185 \mathrm{~m}$. The estimated exposure rate at $1 \mathrm{~m}$ is $70 \mathrm{mR} / \mathrm{h}$ for $1000 \mathrm{~W}$ operation for $1 \mathrm{~h}$, mainly from W-183m (half life $=5.3 \mathrm{~s}$ ) and W-185m (half life $=1.62 \mathrm{~min}$ ). After $1.5 \mathrm{~h}$ decay, the estimated field would be about $4 \mathrm{mR} / \mathrm{h}$ at $1 \mathrm{~m}$. The short-term residual radiation field is not too important for this material, since most of the activity decays away in 1 day.

Using information from Swanson (SWA 79a) on the saturation activity of tungsten activation products, the long-term residual activities of W-181 and Ta-182 in the LEUTL system are estimated to be about $890 \mathrm{mCI}$ and $36 \mathrm{mCi}$, respectively.

\section{Radioactivation of Cooling Water}

Activation of water for cooling the magnets in the system may be estimated in a manner similar to that for radioactivation in air. The primary reactions leading to activation products in water are bremsstrahlung reactions in O-16. Table XXXIb of (SWA 79a) gives the saturation activities of photoactivation products formed in 0-16. The table is based upon 100\% energy absorption in the cooling water; whereas, a more acceptable estimate is that less than $10 \%$ of the energy will be absorbed in the cooling water. This is more reasonable since a fraction of the energy lost (assumed to be $\sim 0.5$ ) will be absorbed in the accelerator components, and a fraction of the remaining energy that escapes into the tunnel is absorbed in air, while some energy will be absorbed in the steel of the magnets or in shielding before reaching the cooling channels.

The most important of the radionuclides produced is O-15. Other products that are formed include C-11 (4.4\% of the O-15 production), $\mathrm{H}-3$ (at saturation, $2.2 \%$ of the $\mathrm{O}-15$ production), $\mathrm{N}-13$ (about $1 \%$ of the $0-15$ production), and $\mathrm{Be}-7$ ( $0.44 \%$ of the $0-15$ production). The production (yield) of 0-15 may be estimated from Equation (28), using an effective $\mathrm{Z}$ of 3.34 for water, according to Schaeffer ( $\mathrm{SCH} 73$ ) and assuming that the $\mathrm{O}-16$ abundance is $100 \%$ :

$$
\mathrm{Y}^{\prime}=1.21 \times 10^{8}(1)(3.34)^{0.66}=2.68 \times 10^{8} \text { atoms } / \text { Ws } .
$$

Because the half life of $\mathrm{O}-15$ is only $2.05 \mathrm{~min}$, it will reach equilibrium (saturation) rapidly. The saturation activity under static conditions will be given by modified Equation (31), in which $f$, the fraction of energy absorbed, is the operational time weighted fraction as used previously:

$$
A=\frac{W f Y^{\prime}\left(1-e^{-x / \lambda}\right)}{3.7 \times 10^{7}}(\mathrm{mCi}),
$$

where $\mathrm{x}$ is the average path length through the water channel in $\mathrm{m}$ (assumed $=0.02 \mathrm{~m}$ ), and $\lambda$ is the average attenuation length in $\mathrm{m}$ (taken as $0.5 \mathrm{~m}$ for $\mathrm{x}$ rays that penetrate to the water channels). Supplying values for the parameters in the equation, one arrives at

$$
\mathrm{A}=0.384 \text { Wf }(\mathrm{mCi}) \text {. }
$$


For purposes of this estimate, the assumption is that $\mathrm{W}=800$ watts on the particle beam dump, $200 \mathrm{~W}$ on the transition piece, and $5.6 \mathrm{~W}$ lost in the beamline, so that the maximum saturation activity $A$ is computed. This assumes that all energy lost in the vacuum chamber, the transition piece, and at the septum contribute to activation and the irradiated water is near the region in which the energy loss occurs. Since the f parameter differs for each loss site, the total activity obtained by Equation (33) must be summed over the three components in the LEUTL tunnel:

$$
A_{\text {Total }}=0.284 \sum_{i=1}^{3} W_{i} f_{i} \text {. }
$$

In a closed, circulating coolant system, the build-up of a radionuclide may be estimated from the following modified expression from Stapleton (STA 89):

$$
\mathrm{dN} / \mathrm{dt}=\mathrm{A}-\lambda_{\mathrm{R}} \mathrm{N}-\mathrm{FRN} / \mathrm{N}+\mathrm{f} F \mathrm{FN} / \mathrm{N}=\mathrm{A}-\left[\lambda_{\mathrm{R}}+\mathrm{FR}\left(1-\mathrm{f}^{\prime}\right) / \mathrm{V}\right] \mathrm{N},
$$

where $\lambda_{R}$ is the radioactive decay constant, $F R / V$ is the water turnover rate (the water flow rate FR divided by the irradiated volume $V$ ), and $f^{\prime}$ is the fraction of the radioactivity remaining after a complete circuit of the closed system $\left(f^{\prime}=e^{-\lambda_{R} \tau}\right.$, where $\tau$ is the circuit transit time). The solution of the above, for $\mathrm{N}=0$ when $\mathrm{t}=0$, is

$$
N=\frac{A}{\lambda_{R}+F R\left(1-f^{\prime}\right) / V}\left(1-e^{-\left[\lambda_{R}+F R\left(1-f^{\prime}\right) / V\right] t}\right)
$$

and the activity, Act, is

$$
A c t=\frac{0.284 \lambda_{R}\left(1-e^{-\left(\lambda_{R}+\frac{F R\left(1-f^{\prime}\right)}{V}\right) t}\right) \sum_{i=1}^{3} W_{i} f_{i}}{\lambda_{R}+\frac{F R\left(1-f^{\prime}\right)}{V}} .
$$

For an assumed transit time of $10 \mathrm{~min}$ and a turnover rate of $0.08 \mathrm{~min}^{-1}$, using the previous power loss $\mathrm{W}$ for each of the components to estimate the radioactivation and assuming saturation conditions for the shorter-lived radionuclides, the estimated total saturation activities of the various radionuclides formed in water can be computed. Based upon $8 \mathrm{~h}$ of operation, equilibrium will be reached for all but Be-7 and $\mathrm{H}-3$. The resulting activities of the components would be: $0.339 \mathrm{mCi}$ of $0-15,2.6 \times 10^{-3} \mathrm{mCi}$ of C-11, $1.09 \times 10^{-2} \mathrm{mCi}$ of $\mathrm{N}-13,4.4 \times 10^{-6} \mathrm{mCi}$ of Be-7 and $2.7 \times 10^{-7}$ $\mathrm{mCi}$ of $\mathrm{H}-3$ in the LEUTL tunnel. In addition, the synchrotron, PAR, and linac total activations are $11.176 \mathrm{mCi}, 1.7 \times 10^{-2} \mathrm{mCi}$, and $0.226 \mathrm{mCi}$, respectively. Any release into the air of the radioactive gases $\mathrm{O}-15, \mathrm{~N}-13, \mathrm{C}-11$ as carbon dioxide and/or $\mathrm{H}-3$ as water vapor will not contribute significantly to any on-site or off-site doses. 
If some of the water is accidentally discharged from the assumed 250,000 gallon closed system, the estimated composite release concentration, $\mathrm{C}_{\mathrm{H}_{2} \mathrm{O}}$, in the discharge would be:

$$
\mathrm{C}_{\mathrm{H}_{2} \mathrm{O}}=\frac{\mathrm{Act}(\mu \mathrm{Ci})}{2.5 \times 10^{5}(\mathrm{gal}) 3.785(1 / \mathrm{gal}) 10^{3}(\mathrm{cc} / 1)}=1.3 \times 10^{-5} \mu \mathrm{Ci} / \mathrm{cc} .
$$

This concentration is below the discharge limits in DOE Order 5400.5 (DOE 90) for any one of the radionuclides in the composite.

Additional water systems in the LEUTL system tunnel (such as the sprinkler system) are located over a meter away from the beam orbit. The radiation fields at these locations should be at least four orders of magnitude less than those at the cooling water so negligible activation of these systems is anticipated.

\section{Soil Activation}

The potential for soil activation is limited since the main radiation component (bremsstrahlung), which is responsible for the majority of the activation, proceeds mainly in the forward direction and is absorbed mainly by machine components, whereas the soil berms are generally at very large angles (almost at right angles) to the direction of maximum bremsstrahlung emission. The giant resonance neutrons, medium-, and high-energy neutrons may be taken as approximately isotropic and have the potential to activate soil after passing through the shield. However, this activation would be a second-order reaction (i.e., bremsstrablung interacts with matter to form GRN, MEN, and HEN that then further interact to produce radionuclides). Since these interaction processes involve another interaction probability (cross section), the yield of secondary products is expected to be much less than that of the activated machine components (first-order reactions), which is already small. In addition, the radiation will be significantly attenuated in passing through the components and local shielding so that the magnitude of any activation of soil is expected to be insignificant.

\section{APS Off-Site Dose Estimates}

Previous estimates of the off-site dose contributions from the various components of the APS system were made in APS-LS-141 Revised (MOE 91). In addition, revisions to these estimates were made in subsequent documents dealing with the specific accelerator components (MOE 93a, 93b, $93 \mathrm{c}$, and 94). With the addition of the LEUTL, a further revision in the estimate has been made. Because all of the components are surrounded by the storage ring, only the storage ring makes a significant contribution to the direct radiation at the nearest boundary (assumed to be $140 \mathrm{~m}$ from the ring). The estimated annual contribution from the storage ring from direct radiation is 2 $\mathrm{mrem} / \mathrm{y}$. The estimated annual contribution from skyshine for the components of the APS system are: $0.4 \mathrm{mrem}$ from the linac, $0.83 \mathrm{mrem}$ from the PAR, $0.05 \mathrm{mrem}$ from the synchrotron, and 2.1 mrem from the storage ring. Adding the estimated $3.48 \mathrm{mrem} / \mathrm{y}$ from the LEUTL gives a total of 
$6.86 \mathrm{mrem} / \mathrm{y}$ from skyshine. The total annual dose off-site at the nearest boundary is then 8.9 mrem.

\section{REFERENCES}

ACG 96 American Conference of Governmental Industrial Hygienists, Threshold Limit Values for Chemical Substances and Physical Agents and Biological Exposure Indices, ACGIH, Cincinnati, OH (1996).

ALS 89 Lawrence Berkeley Laboratory, An ALS Handbook, PUB-643 Rev. 2, Lawrence Berkeley Laboratory, Berkeley, CA (1989).

APS 96 Argonne National Laboratory, Advanced Photon Source Final Safety Assessment Document, APS-3.1.2.1.0, Argonne National Laboratory, Argonne IL (1996).

BAT 67 G. Bathow et al., "Measurements on $6.3 \mathrm{GeV}$ Electromagnetic Cascades and Cascade Produced Neutrons," Nucl. Phys., B2, 669 (1967).

CER 81 K. Goebel, Ed., The Radiological Impact of the LEP Project on the Environment, CERN 81-08 (20 July 1981).

CER 84 A. Fasso et al., Radiation Problems in the Design of the Large Electron-Positron Collider (LEP), CERN 84-02 (5 March 1984).

CFR 94 Code of Federal Regulations, Occupational Radiation Protection, Title 10, Part 835, U.S. Government Printing Office, Washington, DC (1994).

DEC 97 G. Decker et al., "'Maximal Credible Accident' Simulation Studies at the Storage Ring of the APS," Light Source Note, LS-262, Argonne National Laboratory, Argonne, IL (1997).

DOE 90 U.S. Department of Energy, Radiation Protection of the Public and the Environment, DOE Order 5400.5, Washington, DC (Feb. 2, 1990).

DOE 92 U.S. Department of Energy, Safety of Accelerator Facilities, DOE Order 5480.25, Washington, DC (Nov. 3, 1992).

GOD 68 R. P. Godwin, "Synchrotron Radiation as a Light Source," Springer Tracts in Modern Physics, Vol 51, Springer, Berlin/New York (1968).

ICP 87 International Commission on Radiation Protection, Data for Use in Protection Against External Radiation, ICRP Publication 51, ICRP (1987). 
ICR 78 International Commission on Radiation Units and Measurements, Basic Aspects of High Energy Particle Interactions and Radiation Dosimetry, ICRU Report 28, ICRU (1978).

JEN 79 T. M. Jenkins, "Neutron and Photon Measurements Through Concrete from a 15-GeV Electron Beam on a Target - Comparison with Models and Calculations," Nucl. Instrum. Methods, 159,265 (1979).

MIL 97 S. Milton et al., "The Advanced Photon Source Low-Energy Undulator Test Line," Proc. of the 1997 Particle Accelerator Conference, Vancouver, B. C., Canada (May 12$16,1997)$, in press.

MOE 91 H. J. Moe, "Advanced Photon Source: Radiological Design Considerations," ANL Report, APS-LS-141 Revised (July 1991).

MOE 93a H. J. Moe, internal communication to M. White (April 30, 1993).

MOE 93b H. J. Moe, internal communication to M. D. Borland (August 29,1993).

MOE 93c H. J. Moe, internal communication to S. Milton (Sep. 10, 1993).

MOE 94 H. J. Moe, internal communication to G. Decker (July 31, 1994), revised Sep. 24, 1997.

MOE 97 H. J. Moe, internal communication to N. Sereno (Nov. 12, 1996).

NEL 66 W. R. Nelson, "Electron Induced Cascade Showers in Copper and Lead at $1 \mathrm{GeV}$," Phys. Rev., 149, 201 (1966).

NEL 68 W. R. Nelson, "The Shielding of Muons Around High Energy Electron Accelerators: Theory and Measurements," Nucl. Instrum. Methods, 66, (1968).

RIN 75 A. Rindi and R. H. Thomas, "Skyshine - A Paper Tiger?," Part. Accel., 7, 23-29 (1975).

SCH 73 N. M. Schaeffer, Ed., Reactor Shielding for Nuclear Engineers, NTIS, Springfield, VA (1973).

SHE 88 G. K. Shenoy et al., "Characteristics of the 7-GeV Advanced Photon Source: A guide for Users," ANL-88-9, Argonne National Laboratory, Argonne, II (1988).

STA 89 G. Stapleton, "Radiolysis and Radioactivation of Beam Dump Cooling Water," Review of the Radiological Aspects of the Conceptual Design Report for the CEBAF End Stations and Switchyard, CEBAF Report TN-0174 (1989). 
SWA 79 W. P. Swanson, "Improved Calculation of Photoneutron Yields Released by Incident Electrons," Health Phys., 37, 347(1979).

SWA 79a W. P. Swanson, Radiological Safety Aspects of the Operation of Electron Linear Accelerators, Technical Report Series 188, IAEA, Vienna, AUS. (1979), and references therein.

SWA 85 W. P. Swanson et al., Aladdin Upgrade Design Study: Shielding, University of Wisconsin Report (1985).

SWA 87 W. P. Swanson, "Proceedings of the CEBAF Workshop on Radiation Safety," CEBAF Report TN-0058 (1987).

TES 88 K. Tesch, "Shielding Against High Energy Neutrons from Electron Accelerators - A Review," Rad. Prot. Dos., 22, 27 (1988).

TRO 90 G. Tromba and A. Rindi, "Gas Bremsstrahlung from Electron Storage Rings: A Monte Carlo Evaluation and Some Useful Formulae," Nucl. Instrum. Methods, A292, 700 (1990).

TSA 74 Y. S. Tsai, "Pair Production and Bremsstrahlung of Charged Leptons," Rev. Mod. Phys., 46, 815 (1974). 


\section{APPENDIX A \\ Discussion of MCI}

The maximum credible incident $(\mathrm{MCl})$ is that incident which produces the highest dose rate when compared to the dose rates that result from other potential incidents that have been analyzed. It represents the largest risk associated with radiation incidents at the given facility. The incident usually involves postulating equipment failure and/or human error to attain the resultant radiation dose. However, the incident must be considered credible, so that many events that could occur are of such low probability that the event can be considered incredible. That is, one must assume that most, if not all, of the safety systems fail to operate simultaneously with an accompanying equipment failure and/or human error.

The maximum credible incident is defined as occurring when the LEUTL line is set up to run at the safety envelope ( $700 \mathrm{MeV}$ electrons at $1000 \mathrm{~W}$ ) and the linac delivers that power of beam to the synchrotron. For normal operating conditions, one would expect losses in the LEUTL to occur along the line at some low rate. However, in the event that the beam becomes missteered, the loss pattern is not predictable and one could find losses almost anywhere along the line. For the maximum credible incident (MCI), the conservative assumption has been made that the loss takes place in the rising section of the line near the region where it reaches its highest point (see B in Figure 3 of the text). This region is taken as $4 \mathrm{~m}$ in length, at an average height of $2.3 \mathrm{~m}$ in the synchrotron tunnel. The duration of the incident will depend upon the actuation of the shutdown system mechanisms. The dose rate is calculated to give an indication of the potential dose implications if failure of the shutdown mechanisms occur and the incident duration is extended for a significant period of time.

The parameters used in the dose rate assessment are:

- beam energy $700 \mathrm{MeV}$,

- $1000 \mathrm{~W}$ of beam power, $8.92 \times 10^{12} \mathrm{e}^{-/ \mathrm{s}}$ in the beam,

- the total beam dumps along the length of the region (4m), which results in the highest dose rate on the synchrotron mezzanine near the if waveguides,

- the shutdown system fails to shut down the beam within a few pulses,

- the dose point is $2.443 \mathrm{~m}$ perpendicular distance from the loss region and is shielded by 0.16 $\mathrm{cm}$ of $\mathrm{Fe}$ and $100 \mathrm{~cm}$ of concrete,

- an individual is standing on the mezzanine directly above the region of the spill for the duration of the incident.

In a spill, the radiation is emitted along a line source toward the dose point, as shown in the sketch in section 5.1 of the text. The contribution at the point $P$ from the differential line segment $\mathrm{dl}$ for the ith radiation component can be expressed by Equation (9): 


$$
\mathrm{dH}_{\mathrm{i}}=\left[3600 P F_{\mathrm{i}} \prod_{\mathrm{i}, j} \exp ^{-\mathrm{t}_{\mathrm{j}} /(\sin \theta) \lambda_{\mathrm{i}, \mathrm{j}}}\right]_{\mathrm{r}(\theta)^{2}},
$$

where $P$ is the power lost per $m$ of length (W/m), $3600 \mathrm{~s} / \mathrm{h}$ converts $W$ to $J / h, F_{i}$ is the dose constant $(\mathrm{mrem} / \mathrm{J}$ at $1 \mathrm{~m})$ for the ith radiation component, $\mathrm{t}_{\mathrm{j}}$ is the thickness of the jth shield material in $\mathrm{g} / \mathrm{cm}^{2}, \lambda_{i, j}$ is the attenuation length of the ith radiation component for the jth shield material, $r$ is the distance (m) from the differential line segment to the dose point $P$, and $\theta$ is the angle between the line segment and the dose point. The total contribution at the dose point $P$ is given by Equation (10) of the text:

$$
\dot{H}_{i}=3600 P \sum_{i} \int_{-x}^{0} \frac{F_{i} \prod_{i, j} \exp ^{-t_{j} /(\sin \theta) \lambda_{i, j}}}{r(\theta)^{2}} d l .
$$

Since there are four radiation components, each with a different attenuation length in each of the two shields, and each component having its own dose constant that varies with the angle $\theta$ for all but the GRN component, Equation (10) must be numerically integrated to obtain the total dose rate at the point $P$ in the sketch of section 5.1.

The highest total dose rate in the region is $13.1 \mathrm{rem} / \mathrm{h}$. During the MCI, the beam will continue to be lost in the same region at the repetition rate of the linac. Assuming the duration of the incident was as long as 20 minutes, the maximum expected dose under the circumstances would be 4.37 rem. It is equally probable that the spill could occur anywhere along the line in the synchrotron. The expected average dose rate would then be $10.7 \mathrm{rem} / \mathrm{h}$, resulting in a maximum dose of 3.57 rem. 


\section{APPENDIX B Linac Modification to Accommodate rf Test Area and Laser Room}

As part of LEUTL operations, the space at the gun end of the linac will be modified to provide an "rf Test Area" and a "Laser Room," as shown in Figure B-1. Concrete blocks will be used to construct a shielding wall (A) across the entire alcove region at the gun end of the linac. Additional concrete blocks (B) will be used to separate the two areas and provide shielding of the rf Test Area for individuals occupying the Laser Room. All concrete shielding will be $1.016 \mathrm{~m}$ thick. Lead blankets will be used to shield any gaps remaining between the concrete blocks and the ceiling of the linac. Bags containing lead shot will be used to fill voids in cable tray or other penetrations.

In order to estimate the necessary shielding, two measurements were made during linac operation. The first involved using passive dosimeters (TLDs, Albedo, and CR-39) in the area shown in Figure B-2 for the entire duration of a run. The dosimeters were positioned at heights of 3', 6', and $7.5^{\prime}$ above the floor of the linac at the various points indicated in Figure B-2. The region roughly approximates the area to be used for the Laser Room. The second measurement involved the use of portable instruments-Albatross (HPI 2080), Eberline Rem Ball (Eberline ASP-1 with a 9" diameter polyethylene sphere), and an Eberline RO-20-that were placed at locations 1, 2, and 3 in Figure B-1. The Albatross and the Rem ball were used for $n$ measurements, and the RO-20 (an ion chamber) was used for gamma. The response of these instruments while the linac was being run was read by using a TV camera positioned in the linac near the instruments and a monitor outside the linac tunnel.

The passive dosimeter results, shown in Figure B-2, are all in mrem and are listed as $\gamma$ for the photon dose, $\mathrm{A}$ for the Albedo dosimeter dose, and $\mathrm{CR}$ for the CR-39 dose. The Albedo reading indicates the low-energy neutron component (below about $1 \mathrm{MeV}$ ), and the CR-39 reading indicates the high-energy neutron component up to about $20 \mathrm{MeV}$. The general behavior of the results suggests that as one moves away from the linac line (toward the north), the radiation field does not drop off very rapidly. Radiation scattered off the concrete walls of the alcove could contribute to this, as well as a diffuse source of radiation along the linac. At any rate, the results do not suggest an inverse square drop-off of intensity with distance as one moves away from the linac in the northerly direction. As one moves away from the linac toward the east, there is a drop-off in the readings, but also not indicative of an inverse square relationship. In general, the decrease is greater than that for the northerly direction, and the contribution of radiation scattered from the alcove walls is not indicated. These results suggest that the radiation field should be treated as inversely proportional to the distance from the radiation source.

Returning to Figure B-1, the tests with the portable instruments gave information that could be scaled to conditions at the safety envelope. For the positions marked 1 and 3 , the linac gun was run at $30 \mathrm{~Hz}$ (22 gun pulses/s), $220 \mathrm{MeV}$, and $30 \mathrm{nC} /$ pulse; for position 2, the linac gun was run at $2 \mathrm{~Hz}, 220 \mathrm{MeV}$, and $30 \mathrm{nC} /$ pulse. For positions 1 and 3, the rf gun was run at $10 \mathrm{~Hz}$; for position 2 , the rf gun was run at $2 \mathrm{~Hz}$. Readings were taken at all three locations for both linac and if gun operations. The radiation fields measured for position 2 were very much higher than those for 
Figure B-1. Linac modification showing if test area and laser room.

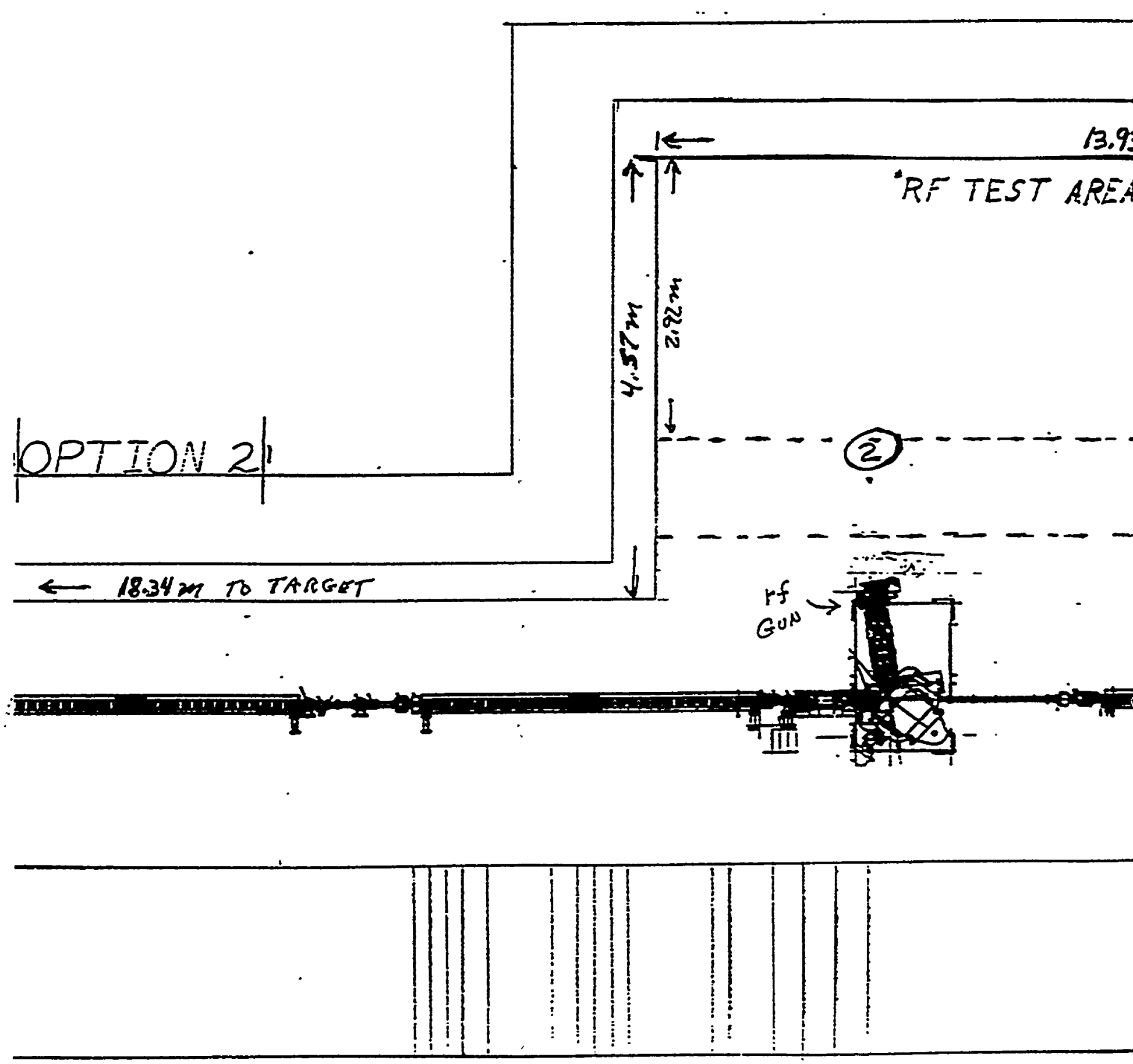




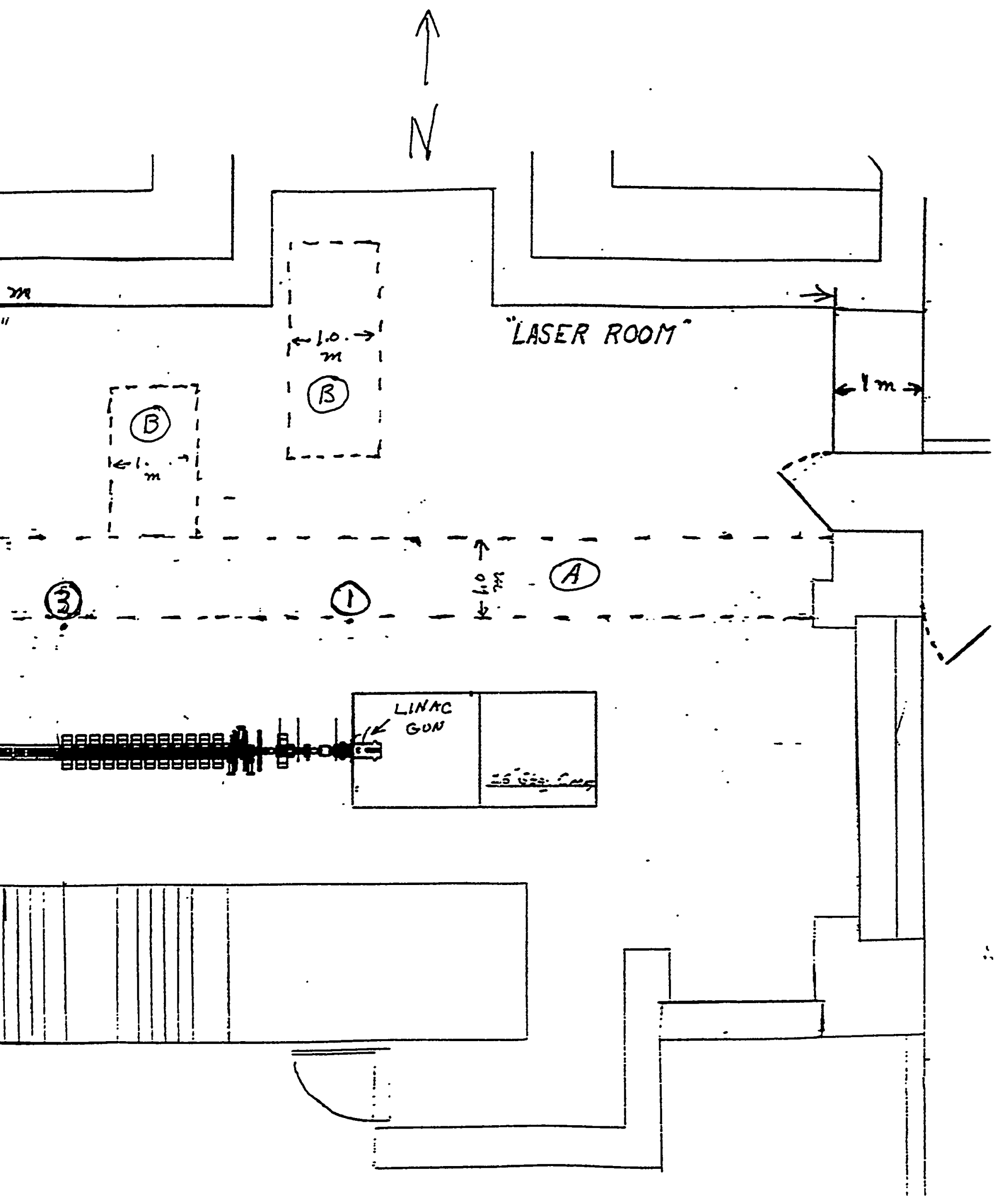


Figure B-2. Passive dosimeter results for Run 1997-7.

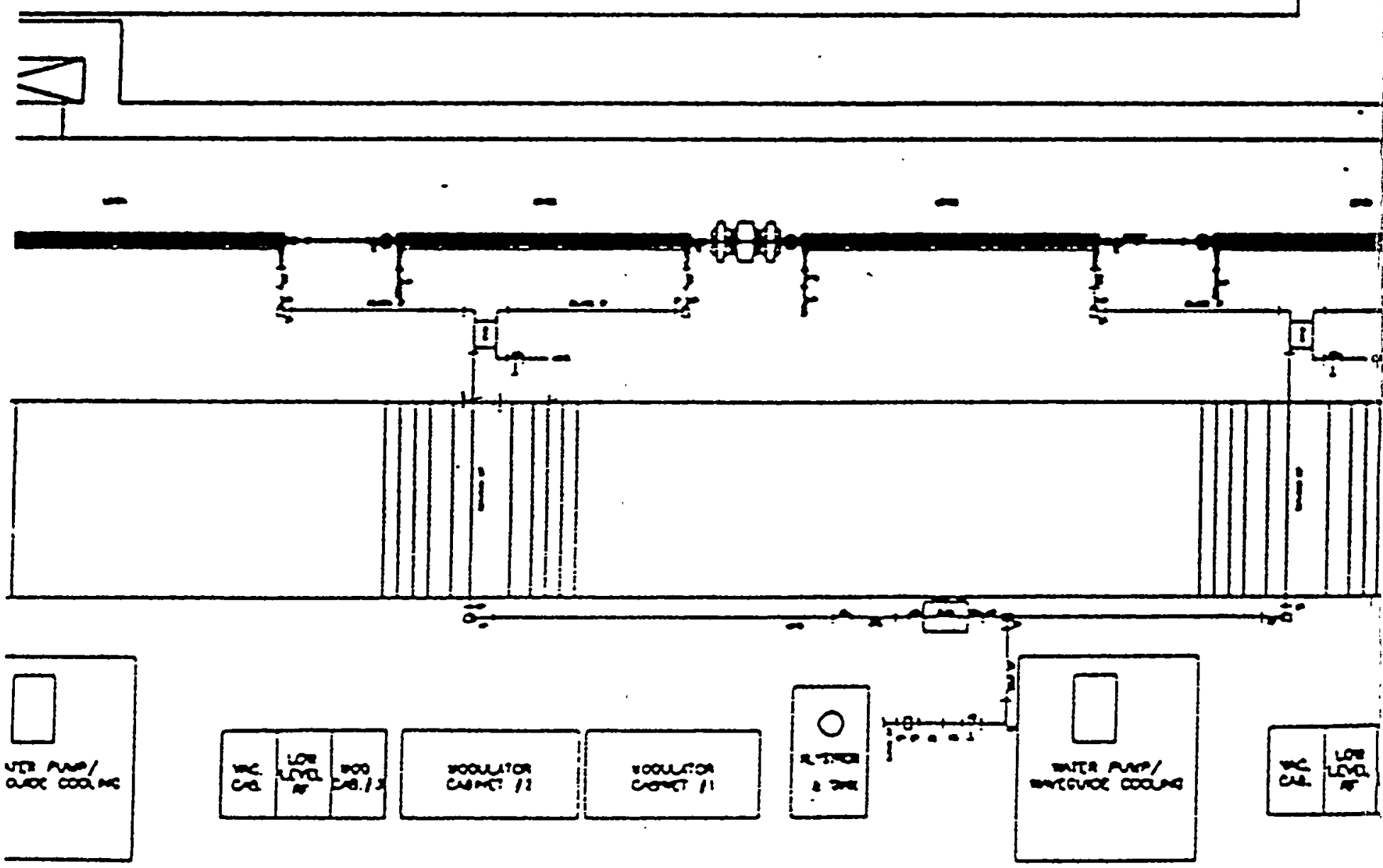




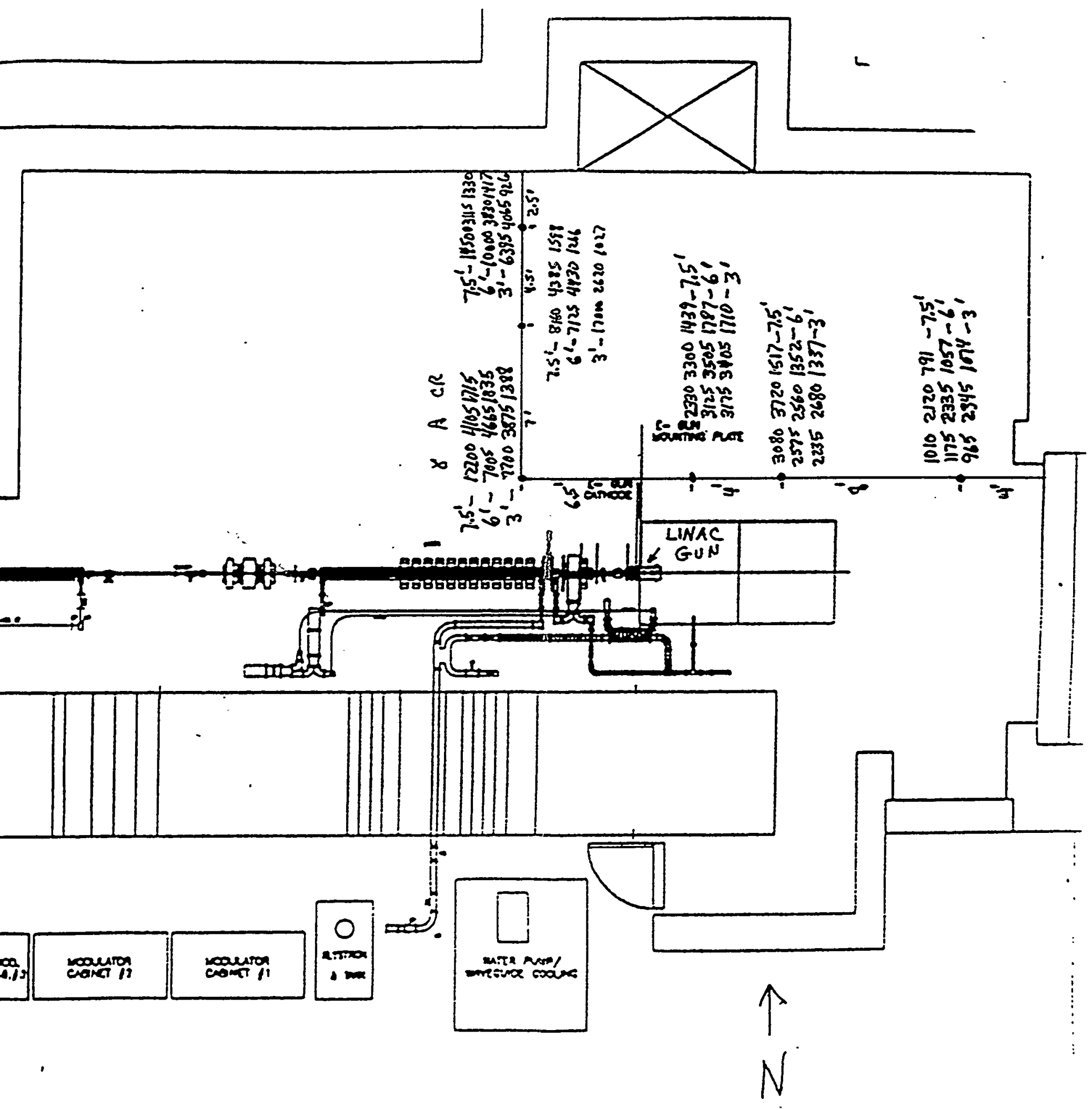

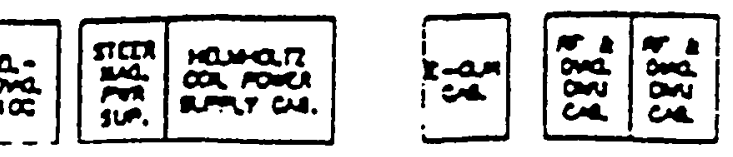


positions 1 and 3 . This made it necessary to run at a reduced pulse rate frequency for position 2 . The results of the measurements at the three locations, normalized to a power level of $145.2 \mathrm{~W}$ $(220 \mathrm{MeV}, 0.66 \mu \mathrm{A})$ for linac gun operation and parameters of $1 \mathrm{~A}, 10 \mathrm{~Hz}$, and $3 \mathrm{MeV}$ (nominal) for $\mathrm{rf}$ gun operation, are shown in Table B-1.

Table B-1. Survey Results for Linac Gun and if Gun Operation

\begin{tabular}{|l|cc|cc|}
\hline \multicolumn{1}{|c|}{ Location } & \multicolumn{2}{|c|}{$\begin{array}{c}\text { Linac Gun Measurements } \\
\text { (mrem/h) }\end{array}$} & \multicolumn{2}{c|}{ If Gun Measurements } \\
& $\mathrm{n}$ & $\gamma$ & $\mathrm{n}$ & $\gamma$ \\
\hline Point 2 & 224.4 & 220 & NA & 5375 \\
\hline Point 3 & 27.6 & 20 & NA & 1067 \\
\hline Point 1 & 19.2 & 4 & NA & 240 \\
\hline
\end{tabular}

With respect to the rf gun data, the drop-off in intensity is more severe than a simple inverse square relationship. The additional reduction in the radiation field could be due to photon absorption in the hardware of the rf gun apparati, which was not accounted for in the calculation. Assume the dose rates at the relevant locations include an additional attenuation of the photons, as well as a point source inverse square drop-off. Using this model and the attenuation length for 3$\mathrm{MeV}$ photons, the dose rate $30 \mathrm{~cm}$ behind a $101.6-\mathrm{cm}$ concrete wall was computed, based upon converting the dose rate at point 2 to the dose rate at $1 \mathrm{~m}$ from the source point. The result was $0.45 \mathrm{mrem} / \mathrm{h}$. Proceeding similarly with the data for point 3, the dose rate in the Laser Room was computed for if gun operation. Due to the slant penetration through the concrete, the dose rate was negligible. These results indicate that the $1.016-\mathrm{m}$ concrete wall will provide adequate shielding in the case of $\mathrm{If}$ gun operation.

The results of the studies with the linac gun are puzzling. When normalized to the safety envelope power, there is a large discrepancy between the point 2 dose rate and that of points 1 and 3 . Assuming a point source along the linac in the vicinity of point 2 , the measurement results for points 1 and 3 show too large a drop-off from the point 2 reading. The drop-off in readings between points 3 and 1 suggests a $1 / \mathrm{r}$ relationship, such as a line source. To estimate the potential dose rates behind the concrete wall in the rf Test Area and the Laser Room, a line source along the linac was assumed. In order not to underestimate the radiation field, the loss rate along the line source was adjusted to give the same reading at point 2 , for operation at the safety envelope with no additional shielding, that was obtained by extrapolating the measurements in Table B-1. This gave projected readings of $552 \mathrm{mrem} / \mathrm{h} \mathrm{n}$ and $542 \mathrm{mrem} / \mathrm{h} \gamma$. The use of this same loss rate gave very conservative projected dose rates for the expected radiation fields at points 1 and 3. Total dose rates were then calculated with the 1.016-m-thick concrete wall in place, using the same line source assumptions, and gave results as shown in Figure B-3. The highest dose rate $(1.92 \mathrm{mrem} / \mathrm{h})$ in the if Test Area would allow restricted entry to this room for short durations. The estimated dose rate in the Laser Room is low enough to allow personnel to occupy this room on a regular basis. The permitted occupancy for each room will be determined by Health Physics personnel who will survey with portable instruments to determine the actual radiation fields with the concrete wall in place. 
Figure B-3. Estimated dose rates in the if test area and the laser room for operation at the linac safety envelope.

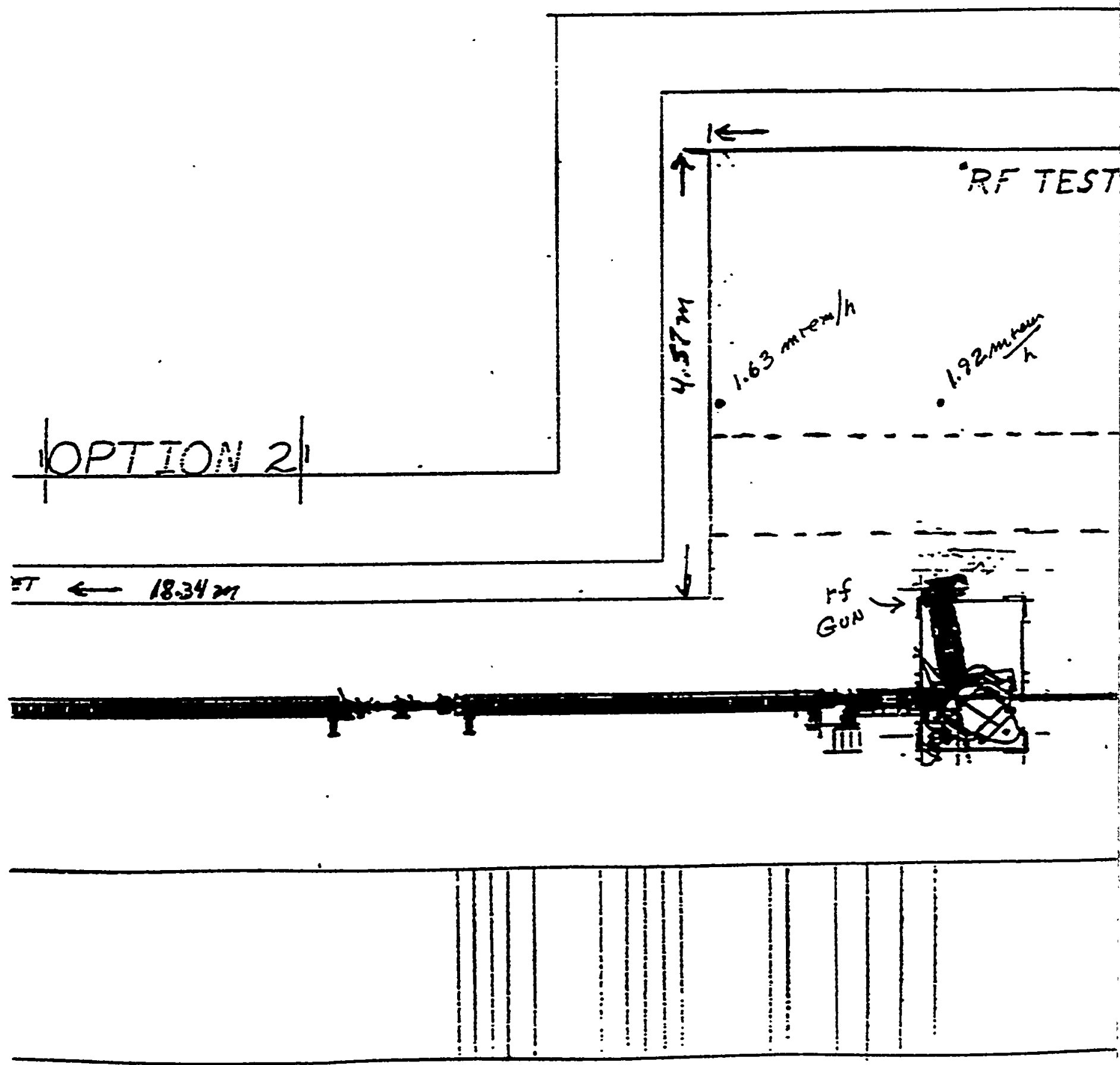


